\title{
A 3-D numerical model of the influence of meanders on groundwater discharge to a gaining stream in an unconfined sandy aquifer
}

Balbarini, Nicola; Boon, Wietse M.; Nicolajsen, Ellen ; Nordbotten, Jan M.; Bjerg, Poul Løgstrup; Binning, Philip John

Published in:

Journal of Hydrology

Link to article, DOI:

10.1016/j.jhydrol.2017.06.042

Publication date:

2017

Document Version

Peer reviewed version

Link back to DTU Orbit

Citation (APA):

Balbarini, N., Boon, W. M., Nicolajsen, E., Nordbotten, J. M., Bjerg, P. L., \& Binning, P. J. (2017). A 3-D numerical model of the influence of meanders on groundwater discharge to a gaining stream in an unconfined sandy aquifer. Journal of Hydrology, 552, 168-181. https://doi.org/10.1016/j.jhydrol.2017.06.042

\section{General rights}

Copyright and moral rights for the publications made accessible in the public portal are retained by the authors and/or other copyright owners and it is a condition of accessing publications that users recognise and abide by the legal requirements associated with these rights.

- Users may download and print one copy of any publication from the public portal for the purpose of private study or research.

- You may not further distribute the material or use it for any profit-making activity or commercial gain

- You may freely distribute the URL identifying the publication in the public portal 
1 A 3-D numerical model of the influence of meanders on groundwater discharge to a

2 gaining stream in an unconfined sandy aquifer

4 Nicola Balbarini ${ }^{1}$, Wietse M. Boon², Ellen Nicolajsen', Jan M. Nordbotten ${ }^{2,3}$, Poul L.

$5 \quad$ Bjerg $^{1}$ and Philip J. Binning ${ }^{1}$

$6{ }^{1}$ Department of Environmental Engineering, Technical University of Denmark, Kgs. Lyngby,

7 Denmark, ${ }^{2}$ Department of Mathematics, University of Bergen, Bergen, Norway, ${ }^{3}$ Department of

8 Civil and Environmental Engineering, Princeton University, Princeton, New Jersey, USA

9

10 Corresponding author: Nicola Balbarini, Department of Environmental Engineering, Technical

11 University of Denmark, Bygningstorvet, Building 115, DK - 2800 Kgs. Lyngby, Denmark,

12 (nbal@env.dtu.dk)

13

14 Journal: Journal of Hydrology

15 Revised submission March 2017

16 Minor revisions May 2017

17

18

19 Key words: Numerical model, 3-D, Meander, Stream geometry, Spatial and temporal variability, 20 Reach scale. 
25 Groundwater discharge to streams depends on stream morphology and groundwater flow direction, but are not always well understood. Here a 3-D groundwater flow model is employed to investigate the impact of meandering stream geometries on groundwater discharge to streams in an unconfined and homogenous sandy aquifer at the reach scale $(10-200 \mathrm{~m})$. The effect of meander geometry was examined by considering three scenarios with varying stream sinuosity. The interaction with regional groundwater flow was examined for each scenario by considering three groundwater flow directions.

31 The sensitivity of stream morphology and flow direction to other parameters was quantified by varying the stream width, the meander amplitude, the magnitude of the hydraulic gradient, the hydraulic conductivity, and the aquifer thickness. Implications for a real stream were then investigated by simulating groundwater flow to a stream at a field site located in Grindsted, Denmark. The simulation of multiple scenarios was made possible by the employment of a computationally efficient coordinate transform numerical method. Comparison of the scenarios showed that the geometry of meanders greatly affect the spatial distribution of groundwater flow to streams. The

38 shallow part of the aquifer discharges to the outward pointing meanders, while deeper groundwater 39 flows beneath the stream and enters from the opposite side. The balance between these two types of 40 flow depends on the aquifer thickness and meander geometry. Regional groundwater flow can 41 combine with the effect of stream meanders and can either enhance or smooth the effect of a meander bend, depending on the regional flow direction. Results from the Grindsted site model showed that 43 real meander geometries had similar effects to those observed for the simpler sinuous streams, and 44 showed that despite large temporal variations in stream discharge, the spatial pattern of flow is almost constant in time for a gaining stream. 


\section{Introduction}

An understanding of the interaction between groundwater and streams is needed to map water

48 fluxes and the transport of contaminants from groundwater into streams (Cey et al., 1998; Derx et al.,

49 2010; Anibas et al., 2012; Karan et al., 2013; Ou et al., 2013; Freitas et al., 2015). This interaction is 50 governed by several factors such as the hydraulic gradient between the aquifer and the stream, the

51 stream channel geometry, and the hydraulic conductivity distribution of the aquifer and the streambed

52 (Larkin and Sharp, 1992; Cey et al., 1998; Krause et al., 2007; Anibas et al., 2012; Binley et al., 2013;

53 Fernando, 2013; Flipo et al., 2014). Furthermore, flow processes between groundwater and streams

54 are scale dependent and so must be investigated at different scales (Dahl et al., 2007; Anibas et al., 55 2012

Flipo

et

al.,

2014; Poulsen

et

al., 2015).

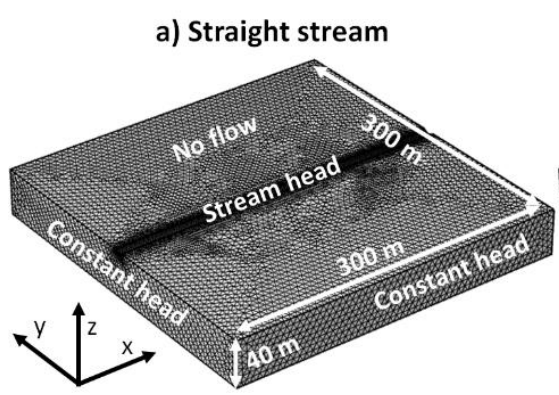

b) Moderately sinuous stream

c) Highly sinuous stream
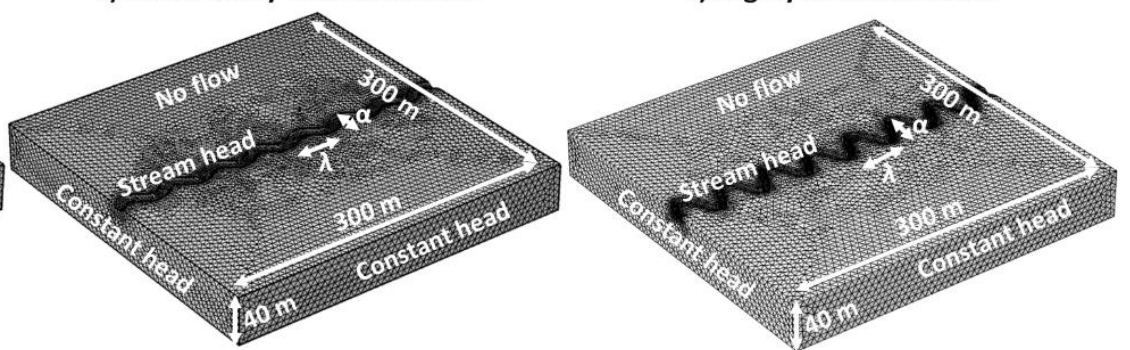


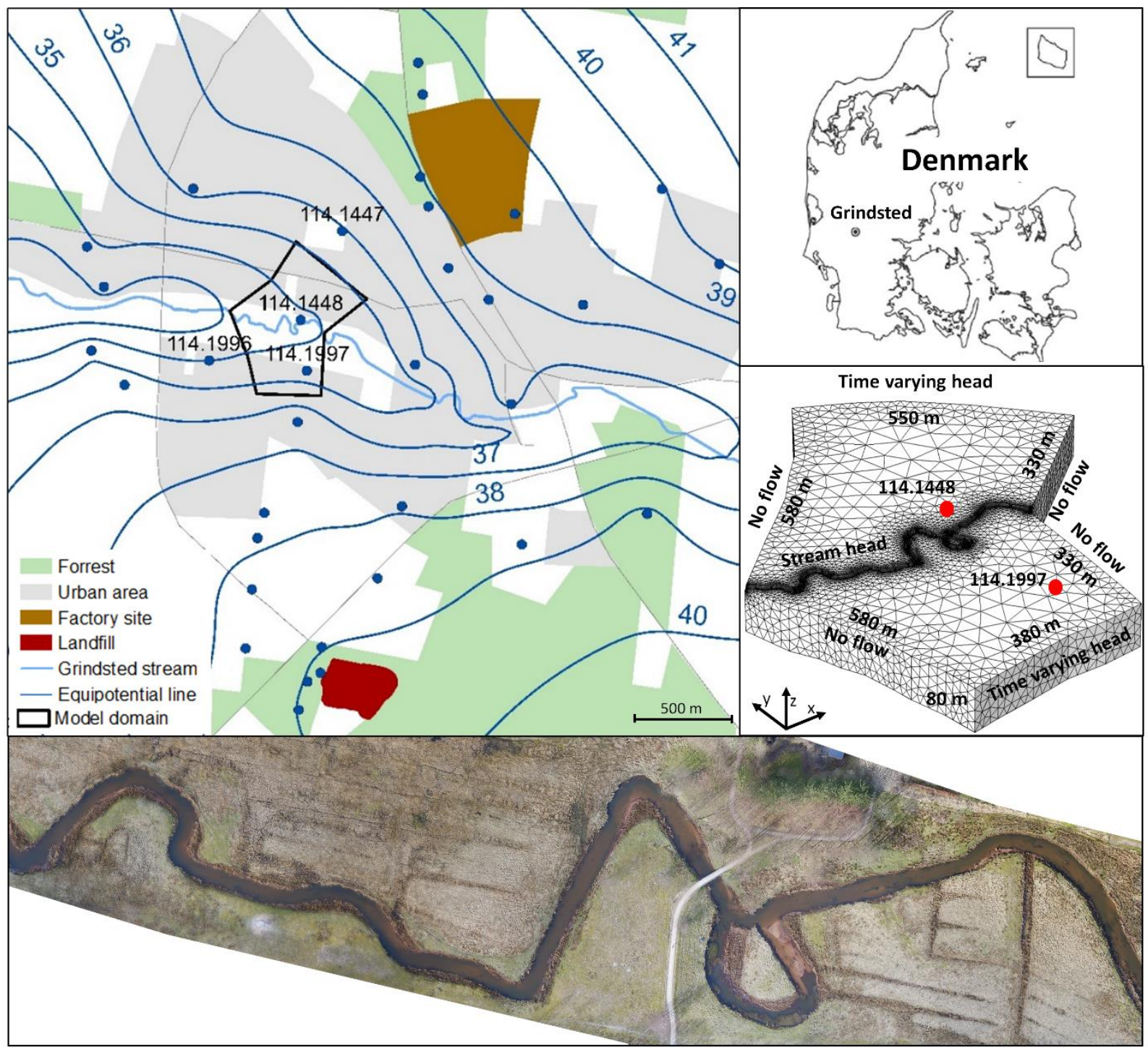

Top surface deformable

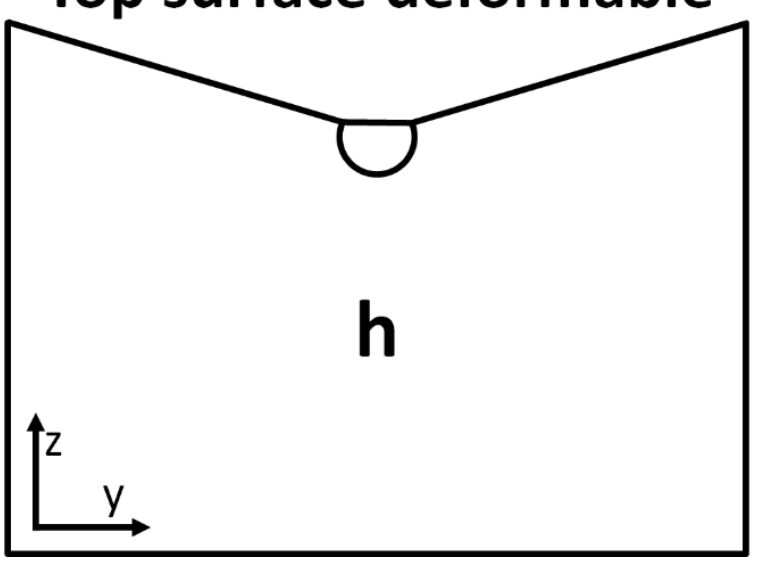

Top surface fixed

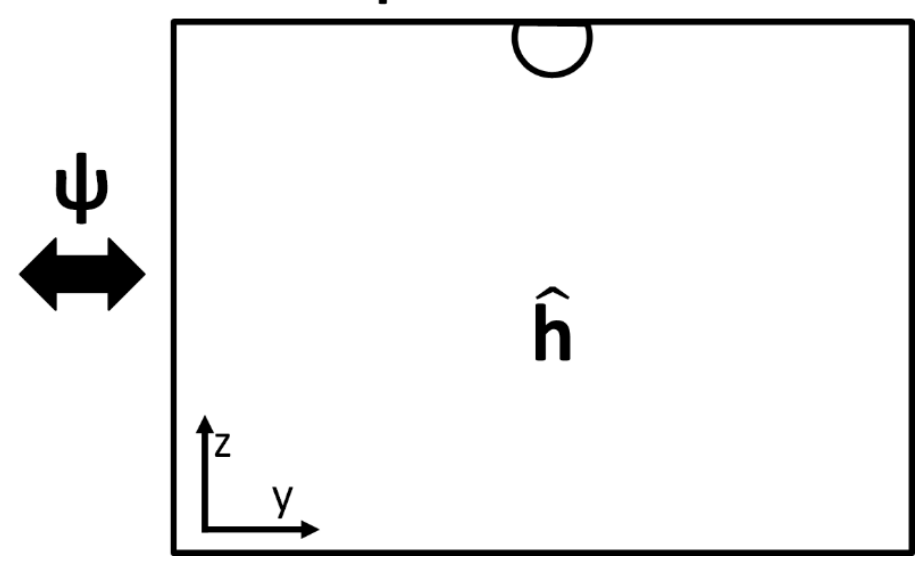




$$
\mathrm{J}_{\mathrm{yx}}=4
$$

$\mathrm{J}_{\mathrm{yx}}=0.5$

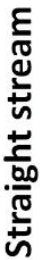

כ)

(a) streamflow (b)

$J_{y x}{ }^{\text {north }}=0.5, J_{y x}{ }^{\text {south }}=0.1$

(c)
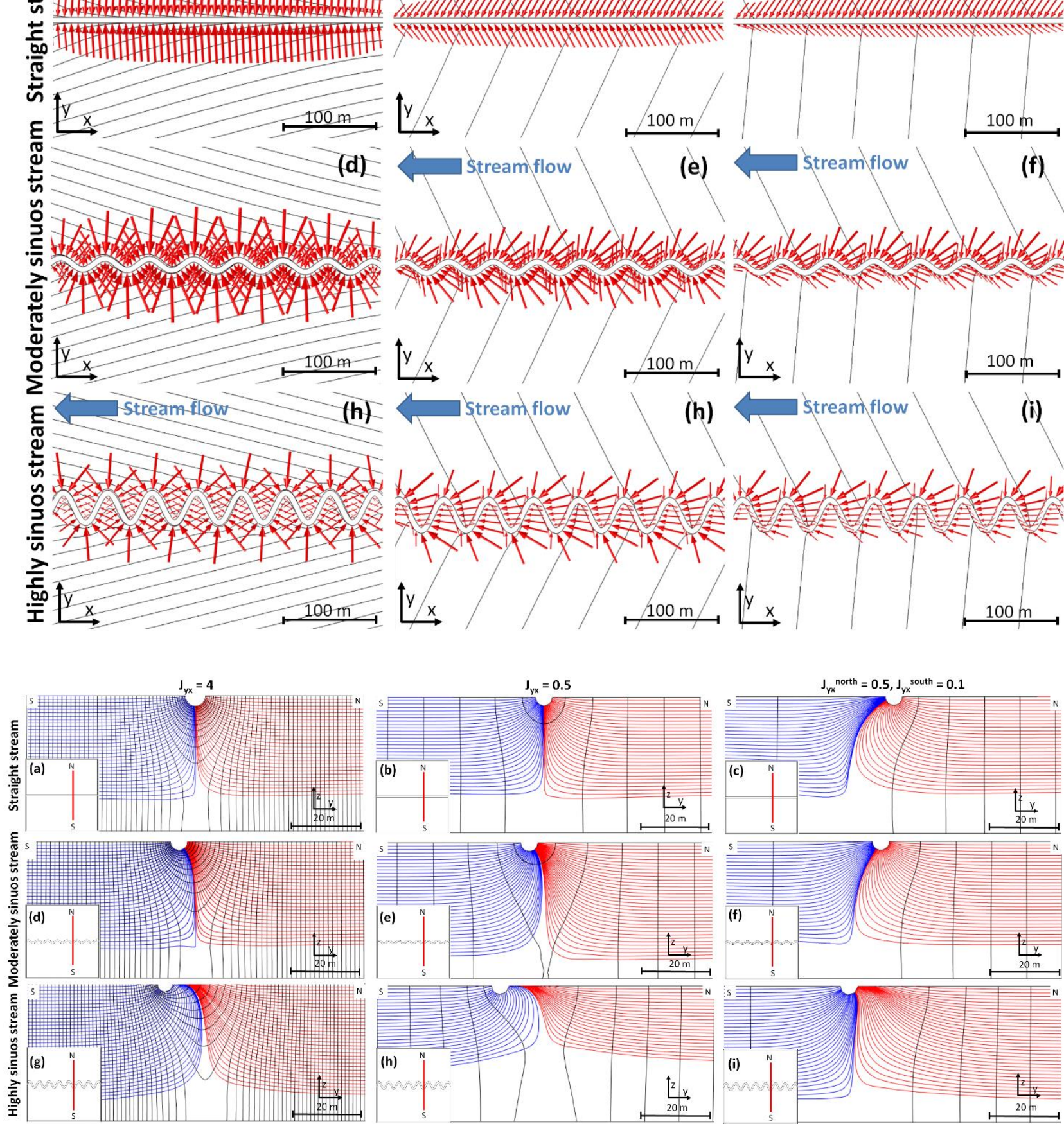


\section{a) $\mathbf{5} \mathrm{m}$ deep aquifer}

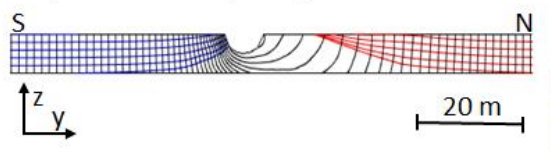

b) $40 \mathrm{~m}$ deep aquifer

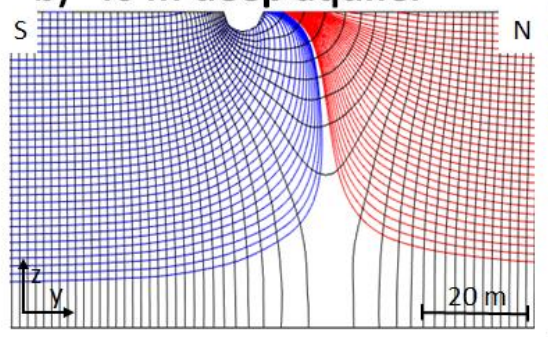

c) $80 \mathrm{~m}$ deep aquifer

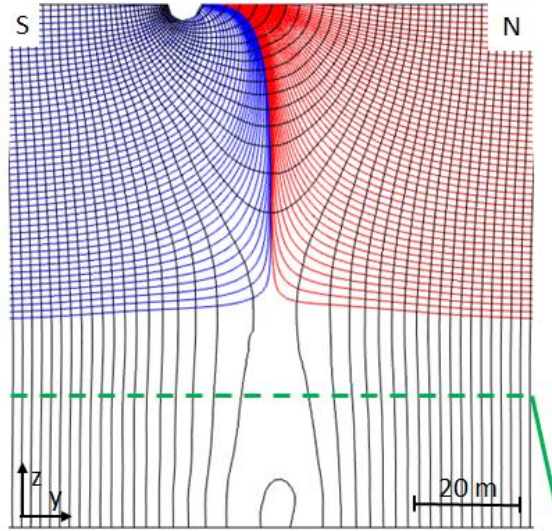

d) Horizontal groundwater flow at 60 mbgs

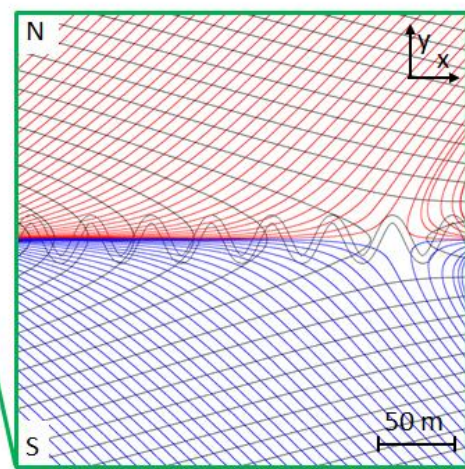

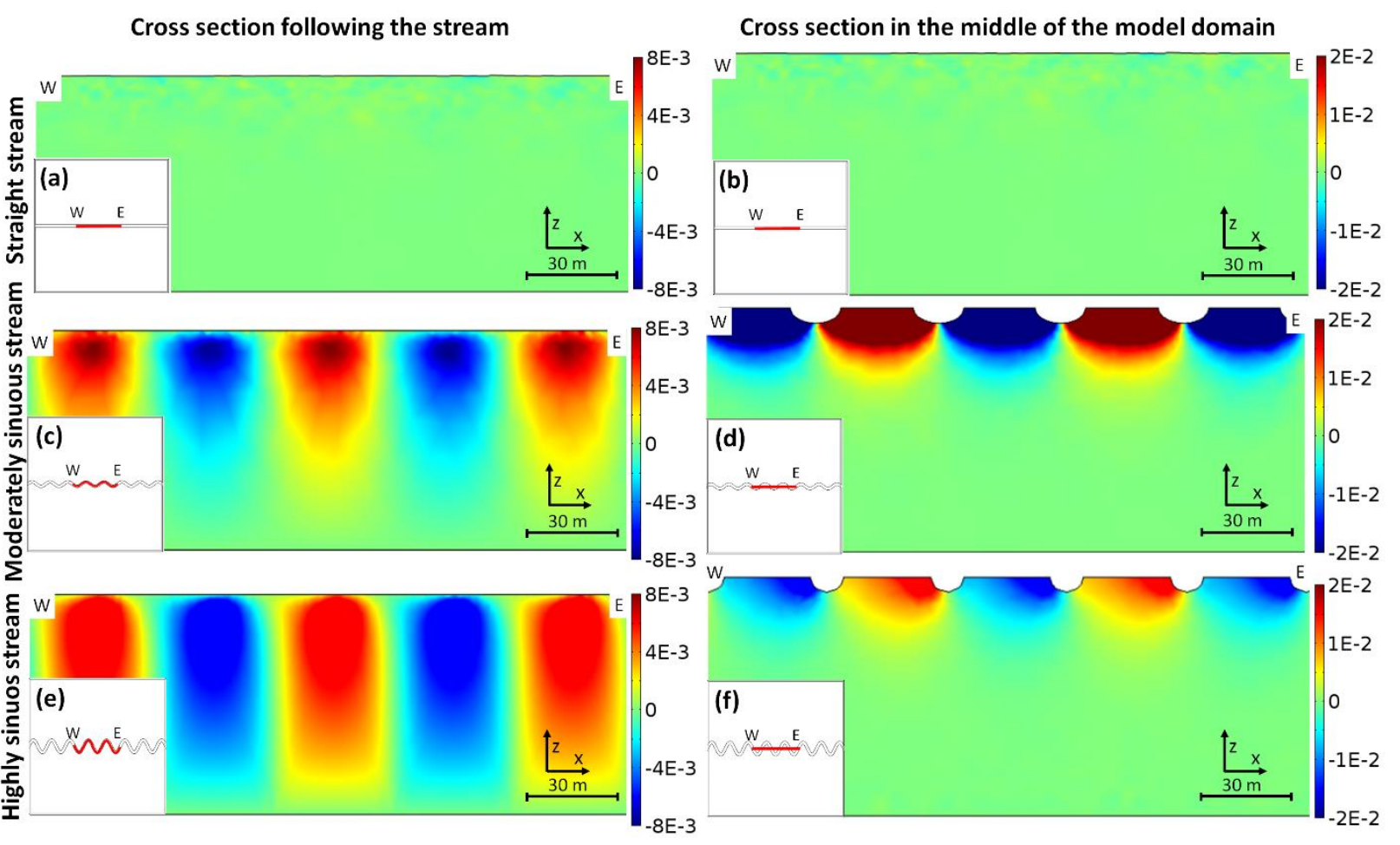




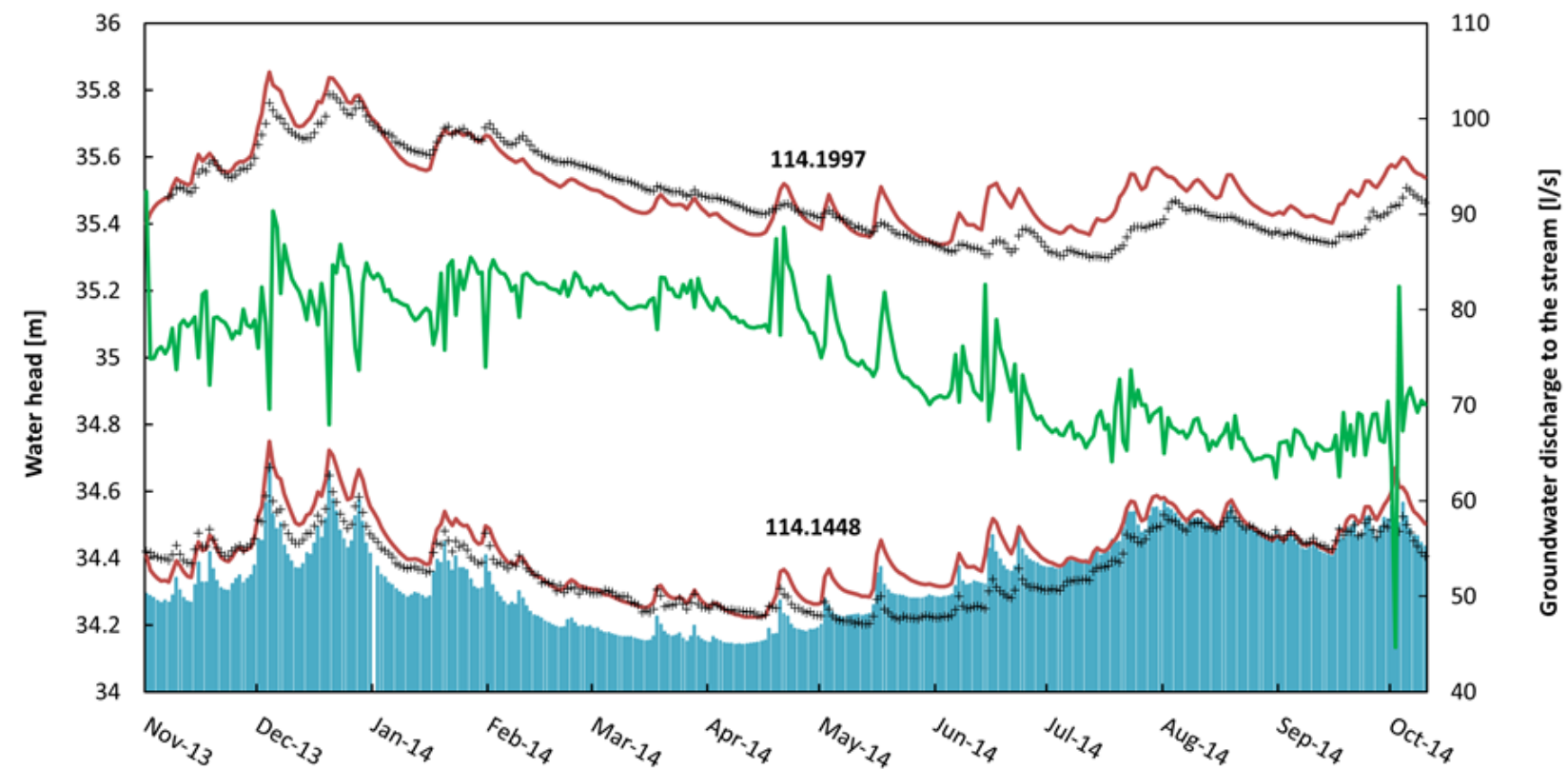

EObserved stream water level + Observed groundwater head -Simulated groundwater head -Simulated groundwater discharge to stream

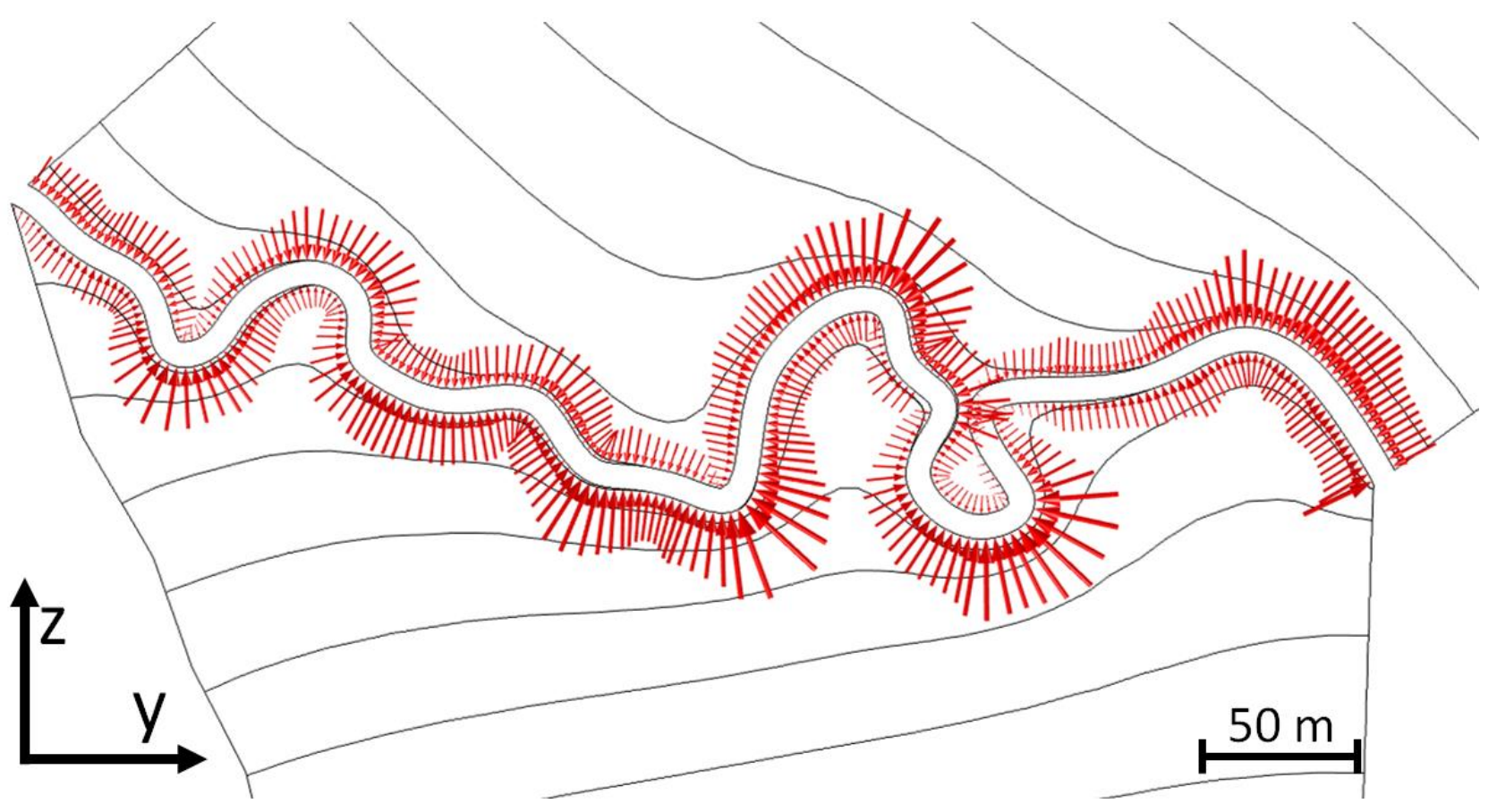




\section{Meander bend pointing north}

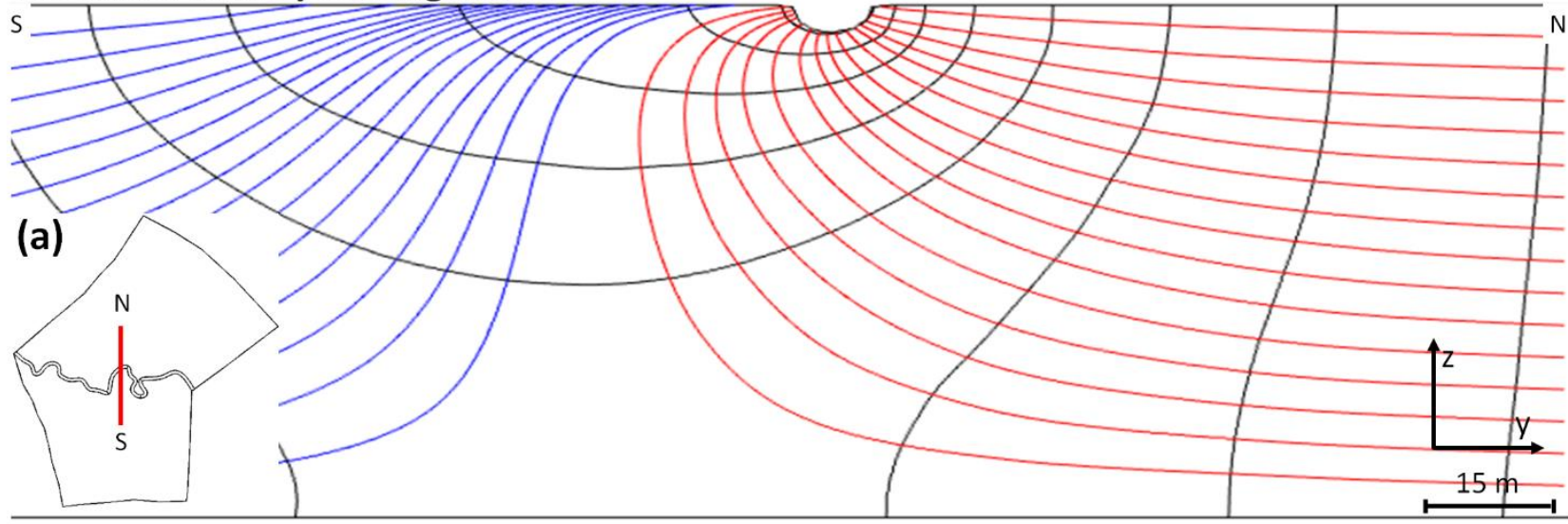

\section{Meander bend pointing south}

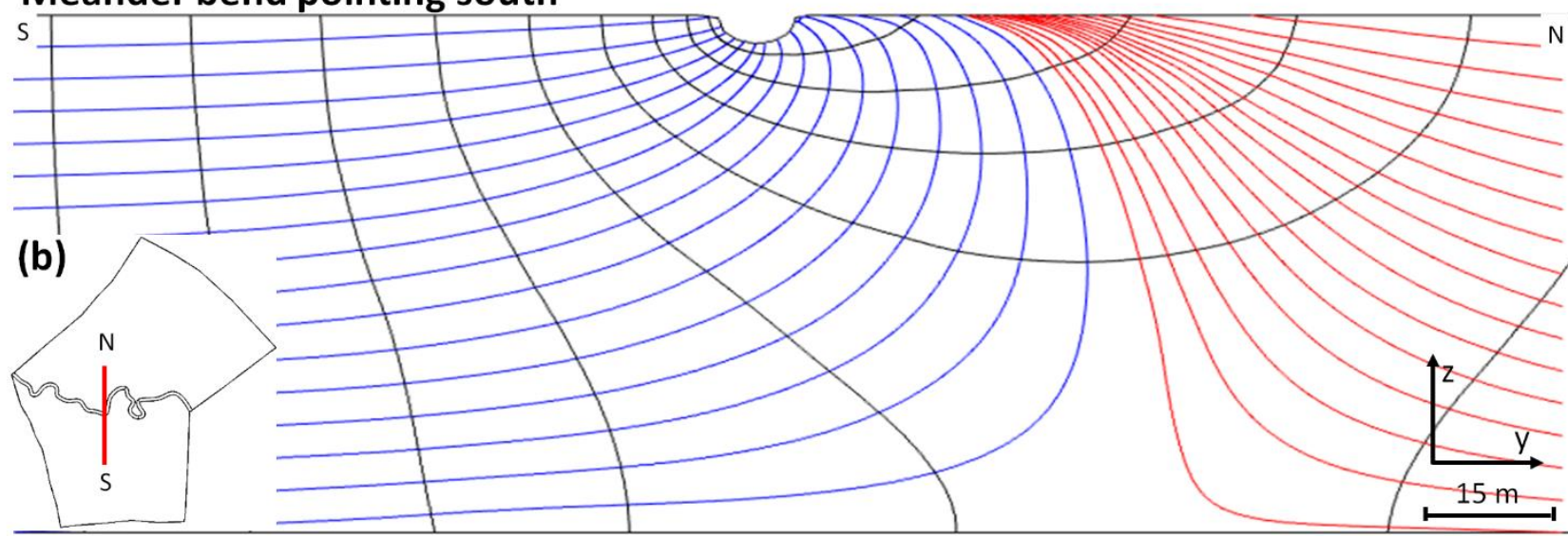

At the reach scale (10-200 m), groundwater flow to streams is both vertical and horizontal; thus,

an analysis in three-dimensions is required (Harvey and Bencala, 1993; Modica et al., 1998; Flipo et al., 2015a; Flipo et al., 2014; Gomez-Velez et al., 2015).

Studies investigating reach scale groundwater flow to streams have generally considered straight streams, and have not accounted for the effect of meander bends (Derx et al., 2010; Guay et al., 2013; Miracapillo and Morel-Seytoux, 2014, see also overview in Table S1). Thus, a better understanding of how groundwater flow varies in space because of stream meanders is needed 
important when investigating contaminant plume discharge to a stream system, where insight is needed to improve site investigations, data interpretation and to design more efficient monitoring campaigns (Harvey and Bencala, 1993; Conant et al., 2004; Anibas et al., 2012; Weatherill et al., 2014). The appropriate scale for contaminant plume studies will often be similar to the stream reach scale (Conant et al., 2004; Byrne et al., 2014; Weatherill et al., 2014; Freitas et al., 2015).

Only a few studies have analyzed groundwater flow to meandering streams (e.g. Dahl et al. (2007), Nalbantis et al. (2011), Flipo et al. (2014), and Boano et al. (2014)). A literature review is shown in Table S1 and shows that the majority of research on meandering stream-aquifer interaction has focused on the hyporheic exchange processes (Wroblicky et al., 1998; Salehin et al., 2004; Cardenas et al., 2004; Cardenas 2008; Revelli et al., 2008; Cardenas, 2009a; Cardenas, 2009b; Boano et al., 2006; Stonedahl et al., 2010; Boano et al., 2009; Boano et al., 2010, Brookfield and Sudicky, 2013; Gomez-Velez et al., 2014; Gomez-Velez et al., 2015). Hyporheic exchange processes take place in the hyporheic zone just under the stream bed, where stream water mixes with groundwater, before returning to the stream. For example, Boano et al. (2010) applied an analytical approach to examine 3-D groundwater flows directly under a streambed, but did not consider the surrounding groundwater flow system.

For many problems, it is necessary to move beyond the hyporheic zone, and consider larger scale groundwater flows at the reach scale. Thus, the focus of this paper is groundwater flow to meandering streams at the reach scale.

This study analyses the spatial variability of the groundwater flow discharge to streams along meander bends in a full 3-D system at the reach scale. The first aim is to simulate the groundwater flow paths to streams and investigate how those paths are affected by stream meanders and groundwater flow direction in an unconfined sandy aquifer. A 3-D numerical model is presented simulating the discharge to streams for a synthetic gaining sinuous stream with three scenarios of 
101 sinuosity: a straight stream, a moderately sinuous stream, and a highly sinuous stream. For each scenario, three groundwater flow directions are assumed with the dominant groundwater flow being: perpendicular to the stream; along the stream; and diagonally across the stream. The resulting groundwater flow to the stream for different sinuosities was quantified for different stream widths, meander geometries, aquifer thicknesses, homogenous hydraulic conductivities, and hydraulic gradients in order to assess the combined effects and the robustness of the results. All numerical models were designed to simulate the groundwater flow to the stream, disregarding the hyporheic flow. The second aim is to apply the 3-D numerical model to a meandering stream at Grindsted in Denmark in order to assess the effects in a field scale system (unconfined, sandy aquifer) with a real 110 geometry and time varying stream water levels. Finally, the implications for our current 111 understanding of discharges to streams are discussed. To address these aims, the 3-D numerical model employed a novel coordinate transformation 113 method developed by Boon et al. (2016). This method solves the equation for groundwater flow in a 114 transformed domain, which is constant in time, while the coordinate system changes depending on 115 the groundwater free surface variations. The application of the linear transformation allows the 116 transformed domain geometry to be simpler than the original problem; thus, the method is 117 computationally efficient and can be applied to complex geometries. Boon et al. (2016) employs the 118 method to simulate groundwater flow to wells, but it has not been applied to other relevant 119 groundwater systems. Since the application of the coordinate transform method to 120 groundwater/surface water interaction is new, it was first tested and compared to existing approaches 121 (the moving mesh and the saturated-unsaturated groundwater flow method). It is shown that the 122 coordinate transform method is far more computationally efficient than the other methods (see 123 Supporting Information, Section S1). 


\section{Method}

\subsection{Sinusoidal stream model}

In this study, the effect of the stream sinuosity on the groundwater flow to streams is analyzed by extending the two-dimensional steady state model developed by Cardenas (2009a; 2009b) to three dimensions. The stream is assumed to be sinusoidal with a constant wavelength $(\lambda)$ of $40 \mathrm{~m}$ and amplitude $(\alpha)$, which is varied in order to reproduce different levels of sinuosity. The sinuosity $(\mathrm{S})$ is calculated by dividing the sinuous stream length along the channel by the straight valley length (300

$131 \mathrm{~m}$ in this study). Three sinuosity scenarios (Figure 1) are considered: a) straight stream ( $\mathrm{S}=1, \alpha=0 \mathrm{~m})$, b) moderately sinuous stream $(S=1.14, \alpha=5 \mathrm{~m})$, and $\mathrm{c})$ a highly sinuous stream $(S=1.74, \alpha=13.5 \mathrm{~m})$. The choices of sinuosity, wavelength, and amplitude are the same as those of Cardenas (2009a; 2009b).

The spatial variability of the groundwater flow to the stream is affected by the stream morphology, the groundwater flow direction, and the distribution of hydraulic conductivities (Krause et al, 2012; Gomez-Velez et al., 2014). In order to isolate and analyze the effect of the stream morphology and the groundwater flow direction, the aquifer is assumed to be homogenous and isotropic with a hydraulic conductivity of $40 \mathrm{~m} / \mathrm{d}$. The stream cross section is a half-ellipsoidal with a depth of $3 \mathrm{~m}$ and a width of $5 \mathrm{~m}$. The stream-aquifer interface is a constant-head boundary where the head varies linearly along the channel with a gradient determined by dividing the overall gradient in the $\mathrm{x}$-direction $(0.001)$ by the sinuosity. Thus, the stream is a gaining stream along the entire length. The top and bottom boundary, except for the stream boundary, are no-flow boundaries and the remaining boundaries are constant-head boundaries. The head gradient is assumed to change linearly depending on the direction.

In order to simulate different groundwater flow directions, the head gradient on the boundary 
gradient is 0.004 for simulating regional groundwater directed laterally toward the stream and 0.0005

149 for regional groundwater flowing in the direction of stream flow. These values were selected based on Cardenas (2009a, 2009b). The third groundwater flow scenario assumes groundwater directed south-west diagonally across the stream, with a boundary gradient in the y-direction of 0.0005 in the area north of the stream and 0.0001 south of the stream.

The effect of the hydraulic gradient on the x-direction (Figure 1) was tested by comparing results for a low gradient of 0.0005 and a high gradient of 0.01 . The effect of the $40 \mathrm{~m}$ constant aquifer thickness was tested by modeling aquifer with thicknesses of $5 \mathrm{~m}$ and $80 \mathrm{~m}$. Similarly, different stream morphologies were tested by varying the stream width between 2 and $10 \mathrm{~m}$, and the meander wavelength between $30(\mathrm{~S}=1.94)$ and $60 \mathrm{~m}(\mathrm{~S}=1.39)$. The effect of the constant hydraulic conductivity was investigated by varying the hydraulic conductivity between 20 and $80 \mathrm{~m} / \mathrm{d}$. These scenarios were simulated for the highly sinuous stream with groundwater flow directed laterally toward the stream.

\subsection{Grindsted stream field site}

To examine the implications of findings for real streams with more complex geometries with time varying boundary conditions, a $500 \mathrm{~m}$ reach scale numerical model of a field site in southern Jutland, Denmark (Figure 2) was constructed. Grindsted stream has a catchment area of approximately $200 \mathrm{~km}^{2}$, is $1-2.5 \mathrm{~m}$ deep and 8-12 $\mathrm{m}$ wide. The unconfined aquifer is $80 \mathrm{~m}$ thick and is in hydraulic contact with the stream. The geology is composed of a Quaternary sand formation for

167 the first 10-15 mbgs and, below that, a Tertiary sand formation. The aquifer is underlain by a thick 168 and extensive Tertiary clay layer at 80 mbgs (Barlebo et al., 1998; Heron et al., 1998). Two 169 contaminated sites are present in the surrounding area: Grindsted factory located $1.5 \mathrm{~km}$ north of the 170 stream, and Grindsted landfill located $2 \mathrm{~km}$ south of the stream (Kjeldsen et al., 1998). From these 171 sites, contaminant plumes discharge into the stream, as evident by examination of stream water 
quality (Rasmussen et al., 2016). The domain of the numerical model was designed in order to include

173 the area where the contaminant plumes discharge to the stream. This paper focuses on an assessment 174 of the 3D groundwater flows to the stream. The analysis of the coupled contaminant transport 175 processes is beyond the scope of this paper and will not be discussed further.

The regional equipotential map (Figure 2) was used to define the lateral extent of the model domain and its geometry. Equipotential boundaries, where the flow is perpendicular to the boundary and the head is constant over depth, are employed (Aisopou et al., 2015b). The remaining boundaries are placed along streamlines where a no-flow condition is assumed on vertical sides. The temporal variability of groundwater flow to streams was modelled accounting for variation in precipitation, 181 stream water level and groundwater head. Precipitation data were collected by the Danish 182 Meteorological Institute at a measurement station at Billund Airport, $15 \mathrm{~km}$ from the study site (DMI, 183 2015). The temporal variation in groundwater heads was monitored at several wells in the Grindsted area (selected wells are shown in Figure 2). Well 114.1996 was used to set the variable head on the southern boundary, adjusting all measured heads by $1.2 \mathrm{~m}$ because the well is not located exactly on the boundary. Similarly, the head at well 114.1447 was applied on the northern boundary, with an 187 adjustment of $0.9 \mathrm{~m}$. The adjustment was made as part of the model calibration in order to fit the 188 simulated with the observed groundwater head level at the two wells located inside the model domain: 189114.1448 and 114.1997. The Quaternary and the tertiary layers are both sandy and have similar 190 hydrogeological properties. Therefore, it was decided to assume a homogenous sandy aquifer. During 191 the model calibration, values of $30 \mathrm{~m} / \mathrm{d}$ for the horizontal hydraulic conductivity and $3 \mathrm{~m} / \mathrm{d}$ for the 192 vertical hydraulic conductivity were selected. These values are being similar to the hydraulic 193 conductivities from other field and model studies in the area (Barlebo et al. 1998; Bjerg et al., 1995; 194 Lønborg et al., 2006). 

of the model domain, and at Eg Bro, located $8.1 \mathrm{~km}$ downstream of the model domain. The average water slope between the two gaging stations is 0.001 . The mean annual stream discharge is $2,150 \mathrm{l} / \mathrm{s}$ at Tingvejen and 2,980 1/s at Eg Bro. The simulated stream reach is about $900 \mathrm{~m}$ long and the annual average groundwater discharge to the stream in the reach, estimated from annual average discharge measurements from the gaging stations, is 70 1/s.

Based on three measured streambed cross sections, the stream cross section is modelled using a half-ellipsoidal with depth of $3 \mathrm{~m}$ and width of $10 \mathrm{~m}$. The depth of $3 \mathrm{~m}$ is larger than the stream water depth to allow for in stream head variations without overbank flow. The stream is implemented as a time varying head boundary where the head varies linearly along the channel with a gradient of 0.001, corresponding to the average water slope between the two gaging stations. The slope of the streambed is assumed to be 0.001 , as to the stream water slope.

\subsection{Modeling groundwater flow to streams with the coordinate transformation method}

The groundwater head at the interface between groundwater and the streambed which controls the flow to/from the stream is temporally variable and is difficult to simulate with a traditional groundwater flow model employing a regular grid. Two methods have been developed to describe

211 the variability of groundwater head in unconfined aquifers: the moving mesh (Knupp, 1996; Darbandi 212 et al., 2007; Bresciani et al., 2011) and the saturated-unsaturated groundwater flow (Freeze, 1971; 213 Sugio and Desay, 1987; Dogan and Motz, 2005; Keating and Zyvoloski, 2009; Camporese et al., 214 2010; Walther et al., 2012). A review of studies applying these methods is provided in Table S2. 215 These methods were developed for unconfined aquifers without considering stream interaction, which 216 introduces large local variations in groundwater head. 
requires re-meshing at each time step, which is very computationally demanding (Freeze, 1971; Kinouchi et al., 1991; Knupp 1996) and can fail for large changes in the water head between time steps or for steep gradients, such as at the stream-aquifer interface (Bresciani et al., 2011; COMSOL, 2013). The saturated-unsaturated method solves the flow equation in both the saturated and unsaturated zone avoiding the problem of explicitly describing the water table surface (An et al., 2010; Kinouchi et al., 1991). However, the method is more computationally demanding than saturated flow models and is rarely justified when the main focus is the saturated flow (Keating and Zyvoloski, 2009).

The new coordinate transformation of Boon et al. (2016) was used to solve the groundwater flow equations in the model domain. The method reduces computational time by employing a coordinate transformation so that the saturated groundwater flow equations are solved on a fixed mesh (Figure 3). For comparison purposes, the equations were also solved on a domain with a dynamically deforming mesh, and by a coupled saturated/unsaturated flow solver (Supporting information S1).

To test the three methods for the groundwater flow to streams problem, they were implemented for a two-dimensional test case and their computational accuracy and efficiency compared (Section 235 S1 in the supporting information). The comparison between the methods shows (Table S4) that the coordinate transformation method is the least computationally demanding of the three methods for a 2-D test problem, requiring 32 times less computational effort than the saturated-unsaturated approach and 3 times less time than moving mesh, for a relatively coarse discretization. Differences

239 become larger in 3-D and when the grid is refined: the computational time required by the moving mesh in a $3-D$ test $(137 \mathrm{~min})$ is 32 times more computational time than the coordinate transformation

241 (4 min). Furthermore, the coordinate transformation method does not lead to instabilities and oscillations, problems that were encountered with the moving mesh. The coordinate transformation 
is a much more computationally efficient solution making it possible to simulate a variety of scenarios and properly explore the problem. Thus, the coordinate transformation method is employed for all examples in this study. saturated conditions is solved in a transformed domain $\widehat{\Omega}$ :

$$
\mathrm{S}_{\mathrm{s}} \frac{\partial \hat{\mathrm{h}}}{\partial \mathrm{t}}+\nabla \cdot(-\widehat{\mathbf{K}} \cdot \nabla \hat{\mathrm{h}})=0 \quad \text { in } \widehat{\Omega}
$$

248 Where Ss is the specific yield $[1 / \mathrm{m}], \widehat{\mathrm{h}}$ is the hydraulic head in the transformed space $[\mathrm{m}]$ and $\widehat{\mathrm{K}}$ is 249 the hydraulic conductivity tensor in the transformed space $[\mathrm{m} / \mathrm{s}]$. The groundwater flow velocity in 250 the transformed domain $\widehat{\Omega}$ becomes:

$$
\widehat{\mathrm{q}}=-\widehat{\mathbf{K}} \cdot \nabla \widehat{\mathrm{h}}
$$

251 The conditions at the top boundary $\Gamma$ are:

$$
\begin{array}{cc}
\hat{\mathrm{h}}(\hat{\mathrm{x}}, \mathrm{t})=\zeta(\hat{\mathrm{x}}, \mathrm{t}) & \text { on } \Gamma \\
-\mathbf{e}_{\Gamma} \cdot(-\widehat{\mathbf{K}} \cdot \nabla \hat{\mathrm{h}})=\left(\mathrm{I}-\mathrm{S}_{\mathrm{y}} \frac{\partial \zeta}{\partial \mathrm{t}}\right) & \text { on } \Gamma
\end{array}
$$

252 where $S_{y}$ is the specific yield [-], $\zeta$ is the elevation for the free surface [-], and $\mathrm{e}_{\Gamma}$ is the unit normal to $253 \Gamma$. The governing equations are solved in Comsol Multiphysics, which employs a finite element 254 numerical approximation (COMSOL, 2013). The finite element method employs the weak form of 255 (1) with a linear polynomial Lagrange test function $g \in \mathrm{H}^{1}(\widehat{\Omega})$ which is combined with the boundary equation (4) and input into COMSOL Multiphysics:

$$
\begin{gathered}
\left(\mathrm{S}_{\mathrm{s}} \frac{\partial \hat{\mathrm{h}}}{\partial \mathrm{t}}+\nabla \cdot(-\widehat{\mathbf{K}} \cdot \nabla \hat{\mathrm{h}}), \mathrm{g}\right)_{\widehat{\Omega}} \\
=\left(\mathrm{S}_{\mathrm{s}} \frac{\partial \hat{\mathrm{h}}}{\partial \mathrm{t}}, \mathrm{g}\right)_{\widehat{\Omega}}+(\widehat{\mathbf{K}} \cdot \nabla \hat{\mathrm{h}}, \nabla \mathrm{g})_{\widehat{\Omega}}+(\mathbf{e} \cdot(-\widehat{\mathbf{K}} \cdot \nabla \hat{\mathrm{h}}), \mathrm{g})_{\Gamma}
\end{gathered}
$$




$$
=\left(\mathrm{S}_{\mathrm{s}} \frac{\partial \hat{\mathrm{h}}}{\partial \mathrm{t}}, \mathrm{g}\right)_{\widehat{\Omega}}+(\widehat{\mathbf{K}} \cdot \nabla \hat{\mathrm{h}}, \nabla \mathrm{g})_{\widehat{\Omega}}-\left(\left(\mathrm{I}-\mathrm{S}_{\mathrm{y}} \frac{\partial \zeta}{\partial \mathrm{t}}\right) \mathrm{e}_{\Gamma_{\mathrm{z}}}, \mathrm{g}\right)_{\Gamma}=0
$$

257 The linear transformation $\psi$ is:

$$
\begin{gathered}
\mathbf{x}=\psi(\hat{\mathrm{x}}, \hat{\mathrm{z}}, \mathrm{t})=[\hat{\mathrm{x}}, 0]+\zeta(\hat{\mathrm{x}}, \mathrm{t}) \hat{\mathrm{z}} \mathbf{e}_{\mathrm{z}} \\
\mathrm{h}(\mathrm{x}, \mathrm{z}, \mathrm{t})=\hat{\mathrm{h}}(\hat{\mathrm{x}}, \hat{\mathrm{z}}, \mathrm{t})
\end{gathered}
$$

258 where $e_{z}$ is the unit vector in the $\mathrm{z}$-direction. The hydraulic conductivity field is a function of the 259 elevation of the free surface $\zeta$ and can be derived from the linear transformation:

$$
\begin{aligned}
\widehat{\mathbf{K}}(\hat{\mathrm{x}}, \hat{\mathrm{z}}, \mathrm{t})=\operatorname{det} & \widehat{\nabla} \psi(\widehat{\nabla} \psi)^{-1} \mathbf{K}\left(\widehat{\nabla}^{\mathrm{T}} \psi\right)^{-1} \\
& =\zeta\left[\begin{array}{cc}
\mathrm{K}_{\mathrm{h}} & -\mathrm{K}_{\mathrm{h}} \hat{\mathrm{z}} \zeta^{-1} \widehat{\nabla} \zeta \\
-\mathrm{K}_{\mathrm{h}} \hat{\mathrm{z}} \zeta^{-1} \widehat{\nabla}^{\mathrm{T}} \zeta & \left(\mathrm{K}_{\mathrm{h}} \hat{\mathrm{z}}^{2} \widehat{\nabla}^{\mathrm{T}} \zeta \widehat{\nabla} \zeta+\mathrm{K}_{\mathrm{v}}\right) \zeta^{-2}
\end{array}\right]
\end{aligned}
$$

260 In equation (8) $\zeta=\zeta(\hat{\mathrm{x}}, \mathrm{t}), \mathrm{K}_{\mathrm{h}}=\mathrm{K}_{\mathrm{h}}(\mathrm{x}, \mathrm{z}), \mathrm{K}_{\mathrm{v}}=\mathrm{K}_{\mathrm{v}}(\mathrm{x}, \mathrm{z})$, and $\widehat{\mathrm{K}}$ depends on the linear transformation 261 described in equation (6) and (7).

Apart from the boundary condition for the top boundary (5), the boundary conditions applied in the transformed domain are: no-flow for the bottom boundary, and time-variable fixed-head for 264 the lateral boundaries. The transform formulation, as well as its numerical implementation using 265 lowest-order Lagrange finite elements is provably stable and convergent (Boon et al., 2016).

\section{Results}

In this section, the effect of meander bends on groundwater flow to streams is presented, with focus on both the vertical and horizontal variability of groundwater flow patterns. The difference between the vertical and horizontal flow could neither have been observed, nor investigated, with a

2-D model. First, the effect of sinuosity is analyzed in combination with other parameters affecting

271 groundwater flow to streams through the synthetic sinuous stream model; then, the results from the Grindsted stream field site are described. 


\subsection{Horizontal variability of the groundwater flow to the stream}

The groundwater discharge to the stream at the upper edge of the stream-aquifer interface is

shown in Figure 4, where the red arrows are proportional to the horizontal groundwater discharge.

Table 1 shows the mean flux over one meander from both stream sides $(\mathrm{m} / \mathrm{s})$ for each scenario and

the percentage of flow discharged at the outward pointing side of the meander and at the inward pointing side of the meander.

The straight stream has a constant discharge along the stream for all hydraulic gradients (Figure $4 a, 4 b$, and $4 c)$, except at the boundaries, where the boundary conditions affected the results. In the moderately sinuous stream (Figure $4 \mathrm{~d}, 4 \mathrm{e}$, and $4 \mathrm{f}$ ), the groundwater discharge to the stream is not constant and changes depending on the location along the stream meander, as shown by the arrow size. The discharge is largest at the extremes of the stream meanders, with $68 \%$ and $67 \%$ of the groundwater flux entering the stream on the outward pointing side of the meanders for a $J_{\mathrm{yx}}$ (ratio between the hydraulic gradient in the y-direction and in the x-direction) of 4 and 0.5 respectively (Table 1). This variation in the groundwater discharge to the stream is due to the stream sinuosity and increases with the sinuosity: $85 \%$ and $82 \%$ of the groundwater flux enters at the outward pointing side of the meander for a $J_{\mathrm{yx}}$ of 4 and 0.5 respectively (corresponding to Figure $4 \mathrm{~g}$ and $4 \mathrm{~h}$ ). This effect can also be seen by comparing Figure $4 \mathrm{~d}$ and $4 \mathrm{e}$ with Figure $4 \mathrm{~g}$, $4 \mathrm{~h}$.

The ratio between the hydraulic gradient in the $\mathrm{y}$ and $\mathrm{x}$-direction $\left(\mathrm{J}_{\mathrm{yx}}\right)$ and, thus, the hydraulic gradient in the y-direction affect the groundwater direction to the stream. In the straight stream, for a large $\mathrm{J}_{\mathrm{yx}}$ (Figure $4 \mathrm{a}$ ), the groundwater direction is more perpendicular to the stream (compared with a lower $\mathbf{J}_{\mathrm{yx}}$ in Figure $4 b$ ). When two different values of $\mathbf{J}_{\mathrm{yx}}$ are applied on each side of the stream (Figure 4c), both the direction of groundwater to the stream and the magnitude of the discharge changes on each side of the stream. A lower value of $\mathrm{J}_{\mathrm{yx}}$ corresponds to a lower groundwater discharge to the stream, as shown on the southern part of the stream in Figure 4c. Therefore, the percentage of 
groundwater flux to the stream is lower (39\%) on the southern side of the stream, where the hydraulic gradient in the y-direction is higher, compared to northern side where the gradient in the y-direction is lower $(61 \%)$.

The effect of the hydraulic gradient can also be observed in the moderately (Figure 4f) and highly sinuous stream (Figure 4i). The highest groundwater flow to the stream is located further upstream on the outward pointing side of the meander bend when decreasing the value of $\mathrm{J}_{\mathrm{yx}}$. Therefore, the groundwater flux on the outward pointing side increases from $67 \%$ to $74 \%$ for the moderately sinuous stream, when the flux is measured on the meander pointing north, where the gradient in the y-direction is higher. The effect of the gradient decreases when the sinuosity increases: for the highly sinuous stream the flux increases from $82 \%$ to $84 \%$.

Table 1: Mean groundwater fluxes to the stream at a meander and percentage of the fluxes entering the stream on the outward pointing side and on the inward pointing side of the meander. The mean flux was calculated as the integral of the discharge along the meander at the stream-aquifer interface divided by the interface area.

\begin{tabular}{|c|c|c|c|c|c|}
\hline Model & Sinuosity & Meander side & $\mathbf{J}_{\mathbf{y x}}=4$ & $J_{\mathbf{y x}}=0.5$ & $\begin{array}{l}\mathbf{J}_{\mathbf{y x}}{ }^{\text {north }}=0.5 \\
\mathbf{J}_{\mathbf{y x}} \text { south }=0.1\end{array}$ \\
\hline \multirow{3}{*}{ Straight stream } & \multirow{3}{*}{1} & Northern side [\%] & 50 & 50 & 61 \\
\hline & & Southern side [\%] & 50 & 50 & 39 \\
\hline & & Mean flux $[\mathrm{m} / \mathrm{s}]$ & 0.58 & 0.06 & 0.04 \\
\hline \multirow{3}{*}{$\begin{array}{l}\text { Moderately sinuous } \\
\text { stream }\end{array}$} & \multirow{3}{*}{1.14} & Outward side [\%] & 68 & 67 & 74 \\
\hline & & Inward side $[\%]$ & 32 & 33 & 26 \\
\hline & & Mean flux $[\mathrm{m} / \mathrm{s}]$ & 0.51 & 0.06 & 0.05 \\
\hline \multirow{3}{*}{$\begin{array}{l}\text { Highly sinuous } \\
\text { stream }\end{array}$} & \multirow{3}{*}{1.74} & Outward side [\%] & 85 & 82 & 84 \\
\hline & & Inward side $[\%]$ & 15 & 18 & 16 \\
\hline & & Mean flux $[\mathrm{m} / \mathrm{s}]$ & 0.48 & 0.05 & 0.05 \\
\hline
\end{tabular}

The results shown in Figure 4 and Table 1 are based on simulations where all parameters are the hydraulic gradient in the $\mathrm{y}$ and $\mathrm{x}$-direction. The fixed parameters include the wavelength of a meander $(40 \mathrm{~m})$, the hydraulic gradient in the $\mathrm{x}$-direction $(1 \%)$, the stream width $(5 \mathrm{~m})$, homogenous hydraulic conductivity $(40 \mathrm{~m} / \mathrm{d})$, and the aquifer depth $(40 \mathrm{~m})$. In order to study how these model 
parameters affect the results shown in Table 1 and Figure 4, the parameters were varied for the scenario with the highly sinuous stream and $J_{\mathrm{yx}}$ of 4 . The results are summarized in Table 2 and Figure

318 S3 (Supporting Information), with bold values indicating the parameter values used for the 319 simulations in Table 1 and Figure 4.

The mean groundwater flux to a stream meander increases with the hydraulic gradient in the $\mathrm{x}-$ direction and with the hydraulic conductivity, as described by Darcy's law: from $0.24 \mathrm{~m} / \mathrm{s}$ to $4.84 \mathrm{~m} / \mathrm{s}$ for a hydraulic gradient of $0.5 \%$ and $10 \%$ respectively, and from $0.25 \mathrm{~m} / \mathrm{s}$ to $0.94 \mathrm{~m} / \mathrm{s}$ for conductivities of $20 \mathrm{~m} / \mathrm{d}$ and $80 \mathrm{~m} / \mathrm{d}$ respectively. However, the percentages of groundwater entering the stream on one side or the other of the meander do not change. This indicates that the magnitude of the hydraulic gradient and of hydraulic conductivity affect the magnitude of groundwater flow entering the stream, but not the direction of the groundwater flow to the stream.

The mean groundwater flux to a stream decreases when increasing the stream width, from 0.53 $\mathrm{m} / \mathrm{s}$ to $0.42 \mathrm{~m} / \mathrm{s}$ for, respectively, a $2 \mathrm{~m}$ and an $8 \mathrm{~m}$ wide stream, because the same discharge enters through a larger area for a larger stream. The percentage of groundwater flux entering the stream on the outward pointing side of the meanders is lower (79\%) for a 2 m wide stream, compared to an $8 \mathrm{~m}$ wide stream $(88 \%)$. In a wider stream, the stream bank on the outward pointing side is closer to the model boundary conditions, leading to a steeper hydraulic gradient and a higher groundwater flux to

333 the stream. Even though the stream width affects the magnitude of the groundwater flux to the stream, 334 it does not affect the direction of groundwater flow to the stream (see Supporting Information, Figure 335 S3).

The wavelength of the stream meanders affects both the average discharge to the stream and 337 the percentage of groundwater entering on each side of a meander bend. The average discharge to the 338 stream is $0.44 \mathrm{~m} / \mathrm{s}$ for the scenario with the wavelength of $30 \mathrm{~m}$, and $0.55 \mathrm{~m} / \mathrm{s}$ with the wavelength 339 of $60 \mathrm{~m}$. The groundwater flux on the outward pointing side of a meander decreases, from $89 \%$ to 
$75 \%$, by increasing the wavelength from 30 to $60 \mathrm{~m}$. When the amplitude of a meander is held

341 constant and the wavelength increases, the sinuosity of the stream decreases. Thus, the flow to the

342 stream is also dependent on sinuosity.

The average groundwater flux increases with increasing the aquifer thickness: from $0.12 \mathrm{~m} / \mathrm{s}$ to $0.64 \mathrm{~m} / \mathrm{s}$ for an aquifer thickness of $5 \mathrm{~m}$ and $80 \mathrm{~m}$ respectively. This can be explained by looking at

345 the depth of the origin of groundwater, discharging to the stream, compared to the depth of the origin

346 of groundwater exiting the model at the downstream boundaries (as seen in Section 3.2 and Figure

347 6). The percentage of water entering the stream on the outward pointing side of a meander is also

348 affected and decreases from $99 \%$ for the $5 \mathrm{~m}$ thick aquifer to $83 \%$ for the $80 \mathrm{~m}$ thick aquifer.

Based on the model sensitivity analysis, the parameters most strongly affecting the spatial

350 distribution of the groundwater flow to a stream are the groundwater flow direction, the stream

351 sinuosity, and the aquifer thickness. The effect of these parameters is further analyzed in Section 3.2

352 where the groundwater flow to the stream in a vertical cross section is examined.

Table 1: Groundwater discharge to the stream at a meander bend. The base parameter values, shown in bold, are the same as those used for the simulation, whose results are summarized in Figure 4, Figure 5, and Table 1. Each parameter is then varied and results shown. The ratio between the hydraulic gradient in the $y$ - and $x$-direction $\left(J_{y x}=4\right)$ and the meander amplitude $(\alpha$ $=13.5$ ) were fixed for these simulations.

\begin{tabular}{|c|c|c|c|c|c|c|c|c|c|c|c|c|c|c|c|}
\hline & \multicolumn{3}{|c|}{ Wavelength [m] } & \multicolumn{3}{|c|}{$\begin{array}{c}\text { Hydraulic } \\
\text { gradient in } x- \\
\text { direction [\%o] }\end{array}$} & \multicolumn{3}{|c|}{$\begin{array}{c}\text { Stream width } \\
{[\mathrm{m}]}\end{array}$} & \multicolumn{3}{|c|}{$\begin{array}{c}\text { Hydraulic } \\
\text { conductivity } \\
{[\mathbf{m} / \mathbf{d}]}\end{array}$} & \multicolumn{3}{|c|}{$\begin{array}{c}\text { Aquifer } \\
\text { thickness [m] }\end{array}$} \\
\hline & 30 & 40 & 60 & 0.5 & 1 & 10 & 2 & 5 & 8 & 20 & 40 & 80 & 5 & 40 & 80 \\
\hline Sinuosity & 1.94 & 1.74 & 1.39 & 1.74 & 1.74 & 1.74 & 1.74 & 1.74 & 1.74 & 1.74 & 1.74 & 1.74 & 1.74 & 1.74 & 1.74 \\
\hline $\begin{array}{l}\text { Outward } \\
\text { side [\%] }\end{array}$ & 89 & 85 & 75 & 85 & 85 & 86 & 79 & 85 & 88 & 85 & 85 & 87 & 99 & 85 & 83 \\
\hline $\begin{array}{l}\text { Inward } \\
\text { side }[\%]\end{array}$ & 11 & 15 & 25 & 15 & 15 & 14 & 21 & 15 & 12 & 15 & 15 & 13 & 1 & 15 & 17 \\
\hline $\begin{array}{c}\text { Mean } \\
\text { flux }[\mathrm{m} / \mathrm{s}]\end{array}$ & 0.44 & 0.48 & 0.55 & 0.24 & 0.48 & 4.84 & 0.53 & 0.48 & 0.42 & 0.25 & 0.48 & 0.94 & 0.12 & 0.48 & 0.64 \\
\hline
\end{tabular}




\subsection{Vertical variability of the groundwater flow to the stream}

In order to analyze the vertical spatial variability of the groundwater close to the stream, the groundwater flow direction on a vertical cross section perpendicular to the stream is shown in Figure 6 with particle tracks to highlight the streamlines: blue for the particles originating south of the stream and red for particles originating from the north. The contour lines (black lines) show the equipotential lines separated by $0.005 \mathrm{~m}$ interval.

In the straight stream (Figure 5a and 5b), the groundwater streamlines enter the stream through the stream bank closest to the boundary of streamline origin. In Figure 5c, the hydraulic gradient in the y-direction is larger on the northern side of the stream compared to the southern side. Here, the groundwater streamlines originating from the north enter the stream on both the northern and southern side of the stream, with the discharging bank depending on the depth of origin of the groundwater flow.

In the moderately sinuous stream and in the highly sinuous stream, the cross section was placed at a point with a meander pointing south. When the hydraulic gradient in the y-direction is the same on both sides of the stream (moderately sinuous stream: Figure 5d and 5e; highly sinuous stream: Figure $5 \mathrm{~g}$ and $5 \mathrm{~h}$ ), the groundwater streamlines originating from the south enter the stream on both the southern and northern side of the stream, with the discharging bank depending on the depth of the groundwater flow. This effect increases with the stream sinuosity, as can be observed by comparing Figure 5d and 5g. Furthermore, a similar, but reversed situation occurs in Figure 5c, where flow patterns are driven by the difference in hydraulic gradient in the y-direction.

In Figure $5 \mathrm{f}$ and $5 \mathrm{i}$, the effects of stream sinuosity and a change in the flow direction at the stream are combined. The two factors have an opposing effect on results; thus, the combined effect 383 is smoothed (compare Figure 5c, 5f, and 5i). In contrast, at meander bends pointing to the north, the effects of the meander bend and the changes in hydraulic gradient reinforce each other. 

the highly sinuous stream with $\mathrm{J}_{\mathrm{yx}}$ of 4 . In the shallow aquifer, which is $5 \mathrm{~m}$ thick, all groundwater discharges to the stream. However, for the $40 \mathrm{~m}$ thick aquifer, groundwater in the top $32 \mathrm{~m}$ discharges to the stream, while the deepest groundwater, in the lowest $8 \mathrm{~m}$ of the aquifer, flows horizontally beneath the stream and is not affected by the stream. Increasing the thickness of the aquifer, from 5 $\mathrm{m}$ to $40 \mathrm{~m}$, results in an increase from 0.12 to $0.48 \mathrm{~m} / \mathrm{s}$ of the average groundwater flux to the stream, as observed in Table 2. When further increasing the aquifer thickness to $80 \mathrm{~m}$, groundwater in the deepest $32 \mathrm{~m}$ of the aquifer flows horizontally downstream without entering the stream, as shown by the horizontal groundwater flow paths in the plan view section 60 mbgs (Figure 6d). The horizontal hydraulic gradient is affected by the stream in the deepest part of the aquifer, while the vertical gradient is not. This indicates that streams have a diminishing effect on groundwater discharge as aquifer thickness increases. Moreover, the area discharging to the stream does not linearly increase with the aquifer thickness. These results are based on three scenarios where the aquifer depth is varied and the stream depth is assumed to be constant. The effect of the stream depth is likely to combine with effect of the aquifer depth, when both parameters are varied. However, this is beyond the scope of this analysis.

The groundwater flow component in the y-direction is shown in Figure 7. The figure shows two 402 cross section: one follows the path to the stream (Figure 7a, 7c, and 7e) while the other is centered in the middle of the model domain (Figure $7 \mathrm{~b}, 7 \mathrm{~d}$, and $7 \mathrm{f}$ ). The results are shown for the straight, the moderately, and the highly sinuous stream scenarios with a constant $J_{\mathrm{yx}}$ of 0.5 . The green color indicates the absence of flow in the $y$-direction, the blue color indicates a negative flow, directed to the south, and the red color indicates a positive flow, directed to the north. 
and a constant aquifer thickness of $40 \mathrm{~m}$, but are valid whenever the hydraulic gradient and the aquifer

410 thickness is constant. The scenario with different hydraulic gradients in the y-direction at the two 411 sides of the stream shows groundwater flow below the stream from north to south, as shown in Figure $4127 \mathrm{c}$.

The moderately sinuous stream (Figure 7c) shows areas colored in blue, associated with a 414 meander pointing toward north, and the areas colored in red, with a meander pointing south. For 415 meanders pointing north, groundwater from the northern side of the stream flows beneath the stream 416 in a southerly direction (the flow has a negative sign), while for meanders pointing south, groundwater 417 from the southern side of the stream flows beneath the stream in a northerly direction (the flow has a 418 positive sign). Between two meander extremes, an area with no flow in the y direction occurs (Figure 419 7c). Y-directional groundwater flow under the stream is greatest for shallow depths and decreases 420 deeper in the aquifer. The same pattern in the groundwater flows can be observed for the highly 421 sinuous stream (Figure 7e), but is more pronounced than for the moderately sinuous stream. The groundwater flow between the northern and southern side of the stream is further analyzed by showing the y-direction flow on a vertical cross section centered in the middle of the model domain (Figure 7b, 7d, and 7f). Curiously, Figure 7d show that the greatest amount of groundwater flow across the stream centerline occurs for the moderately sinuous stream. When sinuosity increases there is less flow inside the meander bend (Figure 4), and a lower y-directional flow across the stream centerline (Figure 7e). This effect is related to the higher discharge to the outward pointing side of a meander bend in the highly sinuous stream, compared to the moderately sinuous stream. In the highly 429 sinuous stream more water enters the stream at the meander bend, instead of crossing the line placed 430 in the middle of the model domain and entering the stream in the inward pointing side of the meander. 


\subsection{Grindsted stream field site}

The model implemented at the Grindsted stream field site was first evaluated by comparing 433 model results with the observed groundwater head and discharge to the stream. In Figure 8, the 434 simulated groundwater head is compared to the observed head at wells located within the model 435 domain: 114.1448 and 114.1997 (Figure 2). In well 114.1448, the model describes the variation 436 groundwater head well, except for the period May-July 2014 when the simulated head (red line) is 437 higher than the observed (black dots). In well 114.1997, the meandering stream model properly 438 simulates the head until June 2014, but the head is overestimated for the remaining simulation time. 439 This is confirmed by the Nash-Sutcliffe efficiency coefficient (Nash and Sutcliffe, 1970) for the entire 440 simulation period of 0.63 and 0.68 at the two observation wells 114.1448 and 114.1997 respectively. 441 The simulated annual average groundwater discharge to the stream is $75 \mathrm{l} / \mathrm{s}$, which matches well the 442 annual averaged discharge estimated from the gaging stations (70 1/s). The inflow at the upgradient 443 groundwater boundaries resembles the discharge to the stream, with small differences due to changes 444 in storage in the domain and recharge.

445 The simulated groundwater discharge to the stream along the entire modeled stream stretch is 446 shown in Figure 8 (green line). The groundwater discharge to the stream varies up to $40 \%$ during the 447 one year simulation. Despite this, the spatial patterns of the groundwater flow to the stream in the 448 simulations are not time varying. This is because the modeled stream is always a gaining stream, and 449 head variations are small (up to 0.4 m over a one year simulation) compared to the aquifer thickness $450(80 \mathrm{~m})$. We carefully note, however, that the spatial patterns of groundwater flow to the stream will 451 probably change with time for a stream that switches between being gaining and losing conditions.

The horizontal groundwater flow at the upper edge of the stream-aquifer interface is shown in 453 Figure 9 by the red arrows, whose length is proportionate to the magnitude of the flow. The 454 groundwater discharge is not constant, but changes depending on the location along the stream. As 
for the sinusoidal stream geometries (Figure 4), the groundwater discharge peaks at the outside extremes of the meander bends and is smallest on the inside of the meander bends.

The groundwater flow to the stream at two vertical cross sections perpendicular to the stream is shown in Figure 10. The cross section in Figure 10a is placed at the location of a meander bend pointing to the north and the cross section in Figure 10b is placed where a meander bend is pointing to the south. In Figure 10a, the particles originating in the shallow part of the aquifer north from the stream enter the stream at the northern bank. The particles originating in the deep part of the aquifer north of the stream enter the stream on the southern bank while the particles coming from the southern side of the aquifer enter the stream on the shallow part of the southern bank. The reverse pattern is observed in Figure 10b. This is similar to the results of the moderately sinuous stream (Figure 5d and 5e) and the high sinuous stream (Figure $5 \mathrm{~g}$ and $5 \mathrm{~h}$ ).

\section{Discussion}

This study shows that meander bends lead to significant spatial variability in groundwater flow to streams. The results show that most of groundwater flowing to the stream enters the stream at the outward pointing side of the meander bend ( $85 \%$ for the highly sinuous stream with a $J_{\mathrm{yx}}$ of 4 ), just upstream of the extremities of the meander (Figure 4 for the synthetic stream and Figure 9 for Grindsted stream). The groundwater discharge to the stream is lowest on the inside of meander bends, where only $15 \%$ of groundwater enters the stream for the highly sinuous stream with a $\mathbf{J}_{\mathrm{yx}}$ of 4 . The amount of groundwater entering the stream is affected by the groundwater flow direction in the aquifer. In case of regional groundwater flowing perpendicularly to the stream direction, $85 \%$ of groundwater discharge occurs on the outward pointing side of a meander, compared to $82 \%$ for regional groundwater flowing in the direction of the stream. In this case, the largest groundwater 
478 Grindsted stream (Figure 9) the variations in the groundwater discharge at the stream-aquifer interface 479 are not as regular as for the synthetic streams (Figure 4). In the synthetic streams, all meanders have 480 the same amplitude and period and are oriented in the same way relative to the groundwater flow 481 direction. In the Grindsted stream, the meanders have different size and are oriented differently. Thus, 482 the spatial variability of the groundwater flow to streams is affected by the size as well as by the 483 orientation of the meander bend.

In the field study of Weatherill et al. (2014), a high concentration of contaminants in 485 groundwater discharge was detected at the outside of a meander bend. Our study, which indicates that 486 the outward pointing side of the bends is the dominant location for groundwater discharge, helps explain those results.

The groundwater flow to the stream is observed to vary greatly with depth for both the synthetic 489 (Figure 5, 6, and 7) and Grindsted streams (Figure 10). This confirms that groundwater flow to streams at meandering streams is three dimensional, as previously suggested by Harvey and Bencala (1993), Modica et al. (1998), and Flipo et al. (2014). The present study investigates how the vertical 492 variability of the groundwater flow to the stream is affected by the meander bends with the 493 discharging bank being dependent on the depth of origin of the groundwater and the stream geometry. 494 The amount of groundwater entering the stream on the opposite bank, increases with the sinuosity 495 (Figure 7a and 7b) and amplitude of the meanders (Figure 5). Curiously the magnitude of the flow 496 crossing the stream center line is highest for moderately sinuous streams and decreases when 497 increasing the sinuosity (Figure 7d and 7e). Groundwater can enter the stream on the opposite bank 498 from its origin because of difference in hydraulic gradient in the aquifer between the two sides of the 499 stream, as occurring when the regional groundwater flow direction is across the stream. The regional 500 groundwater flow can either enhance or smooth the effect of the stream sinuosity, depending on the 501 direction of the regional groundwater flow and the orientation of the meander bends. 
The observation that groundwater can flow below a stream and enter the stream through the opposite bank has previously been described by Aisopou et al. (2015a) and Miracapillo and MorelSeytoux (2014). However, the factors causing groundwater to enter the stream through the opposite bank are different in those papers than here. In Aisopou et al. (2015a), the presence of a pumping well on one side of the stream creates a head gradient that forces groundwater to cross to the opposite side of the stream and enter the stream at the bank closest to the well. In Miracapillo and MorelSeytoux (2014), the difference of the horizontal gradient between the two sides of the stream imposed by the boundary conditions, is responsible for the flow below the stream. Here we focus on the combined influence of stream geometry and groundwater flow direction on the location of groundwater discharge to a stream.

The synthetic stream and the Grindsted stream models have been implemented using different boundary conditions. In the synthetic stream, all the lateral boundary conditions (Figure 1) are constant head and account for the head gradient in the $\mathrm{x}$ and $\mathrm{y}$ direction. In the Grindsted stream model (Figure 2), the boundaries perpendicular to the stream are streamlines (no-flow boundaries) and the upstream groundwater boundaries are fixed-head. The constant head boundaries of the 517 synthetic stream model assume no vertical groundwater gradients. As previously discussed, this is 518 not the case close to a meandering stream. The streamline boundaries applied in the Grindsted stream 519 model allow a vertical gradient. However, the streamline boundaries of the Grindsted model do not 520 allow a horizontal flow across the stream lines in the aquifer. Thus along-stream groundwater flow is 521 better modeled by constant head boundaries. Neither the no-flow nor the constant head boundary 522 conditions perfectly describe conditions under streams. However, this paper has shown that the effect 523 of meanders is similar for both types of groundwater boundary conditions (compare the sinusoidal examples with fixed head boundaries with the Grindsted model with the no flow boundaries). In addition, the results from a larger modeling domain (Figure S4) show that the effect of stream 
meanders on the groundwater flow pattern to the stream do not change when the model boundaries are further from the stream (compare Figure 5i with Figure S4), so the conclusions are robust despite boundary condition uncertainty.

The hydraulic conductivity distribution in the aquifer and in the stream bed is one of the factors, together with the stream morphology and the hydraulic gradient, known to affect the groundwater

531 flow to streams. Recent studies by Krause et al. (2012), Brookfield and Sudicky (2013), Gomez-Velez et al. (2014), and Poulsen et al. (2015) have focused on the effect of the hydraulic conductivity distribution on the groundwater discharge to streams. Since the aim of this study is to investigate the effect of stream meanders and groundwater flow direction on the groundwater flow to streams at the reach scale, the models assume a homogenous sandy aquifer and a constant stream hydraulic gradient.

536 Future studies that investigate the combined effect of stream meanders, varying stream-aquifer hydraulic gradients, and heterogeneous aquifer systems (spatially varying hydraulic conductivity distributions) or layered aquifers would enhance the understanding on groundwater flow to streams.

\section{Conclusions}

A numerical modeling study analyzing the effect of meander bends on the spatial variability of the groundwater flow in an unconfined and homogenous sandy aquifer to a gaining stream at the reach scale is presented. Results were obtained by applying the coordinate transformation method of

543 Boon et al. (2016) to a new problem: the groundwater flow to streams.

The results showed that presence of meander bends leads to significant spatial variability in groundwater discharge to streams. The groundwater fluxes are highest at the meander bend extremes, up to $85 \%$ of the mean fluxes to a meander with a sinuosity of 1.74 , and much lower on the inside of meander bends. This effect increases with the stream sinuosity. The magnitude of the hydraulic gradient of groundwater and of the hydraulic conductivity in the aquifer affects the mean groundwater 
549 flux to the stream, while the stream width and the direction of groundwater affects the groundwater 550 flow direction to the stream. Groundwater gradients combine with the effect of stream meanders and 551 can either enhance or smooth the effect of a meander bend, depending on groundwater flow 552 directions.

The location of the discharge of groundwater along the stream cross section is affected by the 554 stream sinuosity, the direction of the groundwater flow, and the aquifer thickness. At the meander extremes, groundwater coming from the shallow part of the aquifer enters the stream at the outward pointing bank. Groundwater originating from the deep part of the aquifer often flows beneath the stream and enters the stream at the opposite bank at the inward side of a meander bend, with the amount of groundwater flow under the stream increasing with aquifer thickness.

The field site application confirmed the finding of the synthetic study case and showed that the irregular geometry of the stream meanders affects the groundwater discharge to the stream. This study improved our conceptual understanding of the groundwater flow paths to meandering streams in an unconfined homogenous sandy aquifer and shows how stream meanders, combined with groundwater flow direction, affect the spatial variability of the groundwater flow to streams at the reach scale in 564 both synthetic and field systems.

\section{Acknowledgements}

This study was supported by the research project GEOCON, Advancing GEOlogical, 568 1305-00004B). The funding for GEOCON is provided by Innovation Fund Denmark. Additionally, 569 this study was supported by Norwegian Research Council grant 233736. The data used in this paper can be accessed by contacting the first author Nicola Balbarini at nbal@env.dtu.dk. The authors

571 would like to thanks Vinni Rønde, Anne Thobo Sonne and Ursula McKnight for the field data 572 collection and their valuable assistance in the data interpretation. 


\section{References}

574

575

576

577

578

579

580

581

582

583

584

585

586

587

588

589

590

591

592

593

594

595

596

597

598

599

600

601

602

603

604

605

606

607

608

609

Aisopou, A., P. J. Binning, H. Albrechtsen and P. L. Bjerg (2015a), Modeling the factors impacting pesticides concentrations in groundwater wells, Groundwater, 53, 5, $722-736$ doi: 10.1111/gwat.12264.

Aisopou, A., P. L. Bjerg, A. T. Sonne, N. Balbarini, L. Rosenberg and P. J. Binning (2015b), Dilution and volatilization of groundwater contaminant discharges in streams, Journal of Contaminant Hydrology, doi:10.1016/j.jconhyd.2014.11.004.

An, H., Y. Ichikawa, Y. Tachikawa, and M. Shiiba (2010), Three-dimensional finite difference saturated-unsaturated flow modeling with nonorthogonal grids using a coordinate transformation method, Water Resources Research, 46, W11521, doi:10.1029/2009WR009024.

Anibas, C., B. Verbeiren, K. Buis, J. Chorma'nski, L. De Doncker, T. Okruszko, P. Meire and O. Batelaan (2012), A hierarchical approach on groundwater-surface water interaction in wetlands along the upper Biebrza River, Poland, Hydrology and Earth System Sciences, Vol. 16, Pages 2329-2346, doi: 10.5194/hess-16-2329-2012.

Barlebo, H. C., M. C. Hill, D. Rosbjerg and K. H. Jensen (1998), Concentration Data and Dimensionality in Groundwater Models: Evaluation Using Inverse Modelling, Nordic Hydrology, 29, 149-178.

Binley, A., S. Ullah, A. L. Heathwaite, C. Heppell, P. Byrne, K. Lansdown, M. Trimmer and H. Zhang (2013), Revealing the spatial variability of water fluxes at the groundwater-surface water interface, Water Resources Research, Vol. 49, Pages, 3978-3992, doi:10.1002/wrer.20214.

Bjerg, P.L.; Rügge, K.; Pedersen, J.K.; Christensen, T.H. (1995): Distribution of redox sensitive groundwater quality parameters downgradient of a landfill (Grindsted, Denmark). Environmental Science \& Technology, 29, 1387-1394.

Boano F; Camporeale C; Revelli R; Ridolfi L. (2006) Sinuosity-driven hyporheic exchange in meandering rivers, Geophys. Res. Lett., 33, L18406.

Boano, F., R. Revelli, and L. Ridolfi (2009), Quantifying the impact of groundwater discharge on the surface-subsurface exchange, Hydrological Processes, 23, 2108-2126, doi:10.1002/hyp.7278.

Boano, F., C. Camporale and R. Revelli (2010), A linear mode for the coupled surface-subsurface flow in a meandering stream, Water Resources Research, Vol. 46, W07535, doi:10.1029/2009WR008317.

Boano, F., J. W. Harvey, A. marion, A. I. Packman, R. Revelli, L. Ridolfi and A. Wörman (2014), Hyporheic flow and transport processes: Mechanisms, models, and biogeochemical implications, Review of Geophysics, Vol. 52, Pages, 603-679, doi:10.1002/2012RG000417.

Boon, W. M., N. Balbarini, P. J. Binning, and J. M. Nordbotten (2016), Efficient Water Table Evolution Discretization Using Domain Transformation, Computational Geoscience, doi:10.1007/s10596-016-9591-2. 
Bresciani, E., P. Davy, and J. R. De Dreuzy (2011), A finite volume approach with local adaptation scheme for the simulation of free surface flow in porous media, Int. J. Numer. Anal. Methods Geomech., doi: 10.1002/nag.1065

Brookfield, A. E. and E. A. Sudicky (2013), Implications of hyporheic flow on temperature-based estimates of groundwater/surface water interactions, Journal of Hydrologic Engineering, 18(10), pp. 1250-1261.

Byrne, P., A. Binley, A. L. Heathwaite, S. Ullah, C. M. Heppel, K. Lansdown, H. Zhang, M. Trimmer and P. Keenan (2014), Control of river stage on the reactive chemistry of hyporheic zone, Hydrological processes, 28, 4766-4779, doi: 10.1002/hyp.9981.

Camporese, M., C. Paniconi, M. Putti and S. Orlandini (2010), Surface-subsurface flow modeling with path-based runoff routing, boundary condition-based coupling, and assimilation of multisource observation data, Water Resources Research, Vol. 46, doi:10.1029/2008WR007536.

Cardenas, M. B., J. L. Wilson and V. A. Zlotnik (2004), Impact of heterogeneity, be forms, and stream curvature on subchannel hyporheic exchange, Water Resources Research, Vol. 40, W08307, doi:10..1029/2004WR003008.

Cardenas, M. B. (2008), The effect of river bend morphology on flow and timescales of surfacegroundwater exchange across pointbars, Journal of Hydrology, 362, 134-141, doi:10.1016/j.hydrol.2008.08.018.

Cardenas, M. B. (2009a), Stream-aquifer interactions and hyporheic exchange gaining and losing sinuous streams, Water Resources Research, Vol. 45, W06429, doi:10.1029/2008WR007651

Cardenas, M. B. (2009b), A model for lateral hyporheic flow based on valley slope and channel sinuosity, Water Resources Research, Vol. 45, W01501, doi:10.1029/2008WR007442.

Cey, E. E., D. L. Rudolph, G. W. Parkin and R. Aravena (1998), Quantifying groundwater discharge to a small perennial stream in southern Ontario, Canada, Journal of Hydrology, Vol. 210, Pages 21-37.

COMSOL (2013), COMSOL Multiphysics Reference Manual, Version 4.4.

Conant Jr., B., J. A. Cherry, and R. W. Gillham (2004), A PCE groundwater plume discharging to a river: influence of the streambed and near-river zone on contaminant distributions, Journal of Contaminant Hydrology, 73, 249-279, doi:10.1016/j.jconhyd.2004.04.001.

Dahl, M., B. Nilsson, J. H. Langhoff and J. C. Refsgaard (2007), Review of classification systems and new multi-scale typology of groundwater-surface water interaction, Journal of Hydrology, Vol. 344, Pages 1-16, doi:10.1016/j.jhydrol.2007.06.027.

Darbandi, M., S.O. Torabi, M. Saadat, Y. Daghighi, D. Jarrahbashi (2007), A Moving Mesh FiniteVolume Method to Solve Free-Surface Seepage Problem in Arbitrary Geometries, International Journal for Numerical and Analytical Methods in Geomechanics, Vol. 31, Pages 1609-1629. 
Derx, J., A. P. Blaschke and G. Blöschl (2010), Three dimensional flow pattern at the river-aquifer interface-a case study at the Danube, Advances in Water Resources, Vol. 33, Pages 1375-1387.

Diem, S., P. Renard and M. Schirmer (2014), Assessing the effect of different river water level interpolations schemes on modeled groundwater residence times, Journal of Hydrology, Vol. 51, Pages 393-402, doi:10.1016/j.jhydrol.2013.12.049.

DMI (2015), Available from: <http://www.dmi.dk/vejr/> [20 December 2015].

Dogan A. and L. H. Motz (2005), Saturated-unsaturated 3D groundwater model. I: Development, Journal of Hydrologic Engineering, DOI: 10.1061/(ASCE)1084-0699(2005)10:6(492).

Fernando, H. J. S. (2013), Handbook of environmental fluid dynamics, CRC Press, Volume 2, Chapter 2, Pages 19-30.

Flipo, N., A. Mouhri, B. Labarthe, S. Biancamaria, A. Riviere and P. Weill (2014), Continental hydrosystem modelling: the concept of nested stream-aquifer interfaces, Hydrology and Earth System Sciences, Vol. 18, Pages 3121-3149, doi: 10.5194/hess-18-3121-2014.

Freeze, R. A. (1971), Three-Dimensional, Transient, Saturated-Unsaturated Flow in a Groundwater Basin, Water Resources Research, Vol. 7, Pages 347-366, doi:10.1029/WR007i002p00347.

Freitas, J. G., M. O. Rivett, R. S. Roche, M. Durrant, C. Walker and J. H. Tellam (2015), Heterogeneous hyporheic zone dechlorination of a TCE groundwater plume discharging to an urban river reach, Science of the Total Environment, Vol 505, Pages 236-252.

Gomez-Velez, J. D., S. Krause, and J. L. Wilson (2014), Effect of low-permeability layers on spatial patterns of hyporheic exchange and groundwater upwelling, Water Resources Research, doi:10.1002/2013WR015054.

Gomez-Velez, J.D., J.W. Harvey, M.B. Cardenas, and B. Kiel (2015), Denitrification in the Mississippi River network controlled by flow through river bedforms, Nature Geoscience, doi: 10.1038/NGEO2567.

Guay, C., M. Nastev, C. Paniconi and M. Sulis (2013), Comparison of two modeling approaches for groundwater-surface water interactions, Hydrological Processes, Vol. 27, Pages 2258-2270.

Harvey, J. W. and K. E. Bencala (1993), The Effect of Streambed Topography on Surface-Subsurface Water Exchange in Mountain Catchments, Water Resources Research, Vol. 29, No. 1, Pages 89-98.

Heron,G., Bjerg,P.L., Gravesen,P., Ludvigsen,L. \& Christensen,T.H. (1998): Geology and sediment geochemistry of a landfill leachate contaminated aquifer (Grindsted, Denmark). Journal of Contaminant Hydrology, 29, 301-317.

Karan, S., P. Engesgaard, M. C. Looms, T. Laier and J. Kazmierczak (2013), Groundwater flow and mixing in a wetland-stream system: Field study and numerical modeling, Journal of Hydrology, Vol. 488, Pages 73-83. 
Keating, E. and G. Zyvoloski (2009), Saturated-unsaturated 3D groundwater model. I: Development, Ground Water, Vol. 4, Pages 569.579, doi: 10.1111/j.1745-6584.2009.00555.x.

Kinouchi, T., M. Kanda and M. Hino (1991), Numerical simulation of infiltration and solute transport in an S-shaped model basin by a boundary-fitted grid system, Journal of Hydrology, Vol. 122, Pages 373-406, doi:10.1016/0022-1694(91)90189-O.

Kjeldsen, P., P. L. Bjerg, K. Rügge, T. H. Christensen, J. K. and Pedersen, (1998), Characterization of an old municipal landfill (Grindsted, Denmark) as a groundwater pollution source: Landfill hydrology and leachate migration, Waste Management and Research, Vol 16, no. 1, pp. 14-22., doi:10.1177/0734242X9801600103.

Knupp, P. (1996), Moving mesh algorithm for 3-D regional groundwater flow with water table and seepage face, Advances in Water Resources, Vol. 19, No. 2, Pages 83-95.

Krause, S., A. Bronstert and E. Zehe (2007), Groundwater-surface water interactions in a north German lowland floodplain - Implications for the river discharge dynamics and riparian water balance, Journal of Hydrology, Vol. 347, Pages 404-417, doi:10.106/j.jhdrol.2007.09.028.

Krause, S., T. Blume, and N. J. Cassidy (2012), Investigating patterns and controls of groundwater up-welling in a lowland river by combining Fibre-optic Distributed Temperature Sensing with observations of vertical hydraulic gradients, Hydorlogy and Hearth System Sciences, 16, 1775 1792, doi:10.5194/hess-16-1775-2012.

Krause, S., F. Boano, M. O. Cutchbert, J. H. Fleckenstein and J. Lewandowski (2014), Understanding process dynamics at aquifer-surface water interfaces: An introduction to the special edition section on modeling approaches and novel experimental technologies, Water Resources Research, Vol. 50, Pages 1847-1855, doi: 10.1002/2013WR014755.

Larkin R. G. and J. M. Sharp (1992), On the relationship between river-basin geomorphology, aquifer hydraulics, and ground-water flow direction in alluvial aquifers, Geological Society of American Bulletin, V. 104, P. 1608-1620.

Lønborg, M.J., Engesgaard,P., Bjerg,P.L. \& Rosbjerg,D. (2006): A steady state redox zone approach for modeling the transport and degradation of xenobiotic organic compounds from a landfill site. Journal of Contaminant Hydrology, 87, 191-210.

Miracapillo, C., and H. J. Morel-Seytoux (2014), Analytical solutions for stream-aquifer flow exchange under varying head asymmetry and river penetration: Comparison to numerical solutions and use in regional groundwater models, Water Resour. Res., 50, 7430-7444, doi:10.1002/2014WR015456.

Modica, E., H. T. Buxton and L. N. Plummer (1998), Evaluating the source and residence time of groundwater seepage to streams, New Jersey Coastal Plan, Water Resources Research, Vol. 34, No. 11, Pages 2797-2810.

Nalbantis, I., A. Efstratiadis, E. Rozos, M. Kopsiafti and D. Koutsoyiannis (2011), Holistic versus monometric strategies for hydrological modelling of human-modified hydrosystems, Hydrology and Earth System Sciences, Vol. 15, Pages 743-758, doi:10.5194/hess-15-743-2011. 
Nash, J. E. and J. V. Sutcliffe (1970), River flow forecasting through conceptual models part I - A discussion of principles, Journal of Hydrology, 10 (3), 282-290, doi: 10.1016/00221694(70)90255-6

Ou, G., X. Chen, A. Kilic, S. Bartelt-Hunt, Y. Li and A. Samal (2013), Environmental Modelling \& Software, Vol. 50, Pages 132-143.

Poulsen, J. R., E. Sebok, C. Duque, D. Tezlaff and P. K. Engesgaard (2015), Detecting groundwater discharge dynamics from point-to-catchment scale in a lowland stream: combining hydraulic and tracer methods, Hydrology and Earth System Sciences, 19, 1871-1886, doi:10.5194/hess19-1871-2015

Rasmussen, J. J., U. S. McKnight, A. T. Sonne, P. Wiberg-Larsen and P. L. Bjer (2016), Legacy of a chemical factory site: Contaminated groundwater impacts stream macroinvertebrates, Arch Environ Contam Toxicol, doi: 10.1007/s00244-015-0211-2.

Revelli, R., F. Boano, C. Camporale, and L. Ridolfi (2008), Intre-meander hyporheic flow in alluvial rivers, Water Resources Research, Vol. 44, doi:10.1029/2008WR007081.

Salehin, m., A. I. Packman, and M. Paradis (2004), Hyporheic exchange with heterogenous streambeds: Laboratory experiments and modeling, Water Resources Research, V1. 40, W11504, doi:10.1029/2003WR002567.

Stonedahl, S. H., J. W. Harvey, A. Wörman, M. Salehin and A. I. Packman (2010), A multistate model for integrating hyporheic exchange from rippleds to meanders, Water Resources Management, Vol. 46, W12539, doi:10.1029/2009/WR008865.

Sugio S. and C. S. Desai (1987), Residual flow procedure for sea water intrusion in unconfined aquifers, journal of numerical methods in engineering, Vol. 24, 1439-1450.

Toth, J. (1963), A Theoretical Analysis of Groundwater Flow in Small Drainage Basins, Journal of Geophysical Research, Vol. 68, No. 16, Pages 4795-4812.

Walther, M., J.-O. Delfs, J. Grundmann, O. Kolditz, and R. Liedl (2012), Saltware intrusion modeling: Verification and application to an agricultural coastal arid region in Oman, Journal of Computational and Applied Mathematics, 236, 4798-1809, doi:10.1016/j.cam.2012.02.008.

Weatherill, J., S. Krause, K. Voyce, F. Drijfhout, A. Levy and N. Cassidy (2014), Nested monitoring approaches to delineate groundwater trichloroethene discharge to a UK lowland stream at multiple spatial scales, Journal of Contaminant Hydrology, Vol. 158, Pages 38-54.

Wroblicky, G. J., M. E. Campana, H. M. Valett and C. N. Dahm (1998), Seasonal variation in surfacesubsurface water exchange and lateral hyporheic area of two stream-aquifer systems, Water Resources Research, Vol. 34, No. 3, Pages 317-328 


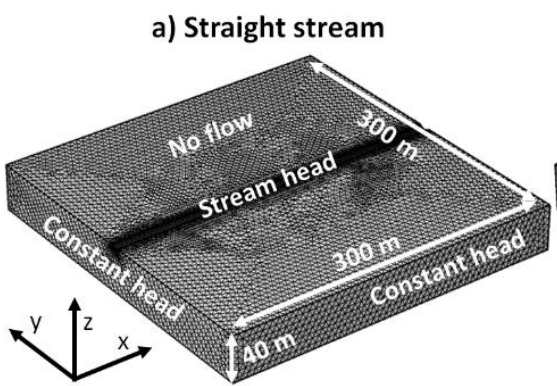

b) Moderately sinuous stream
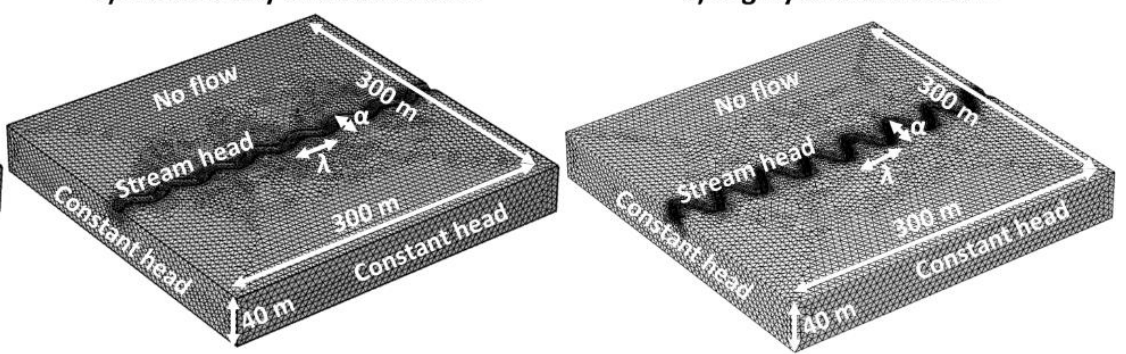

Figure 1: Model domain, finite element mesh, and boundary conditions for the three scenarios of the synthetic stream model: straight stream (a), the moderately sinuous stream (b), and the highly sinuous stream (c) models.

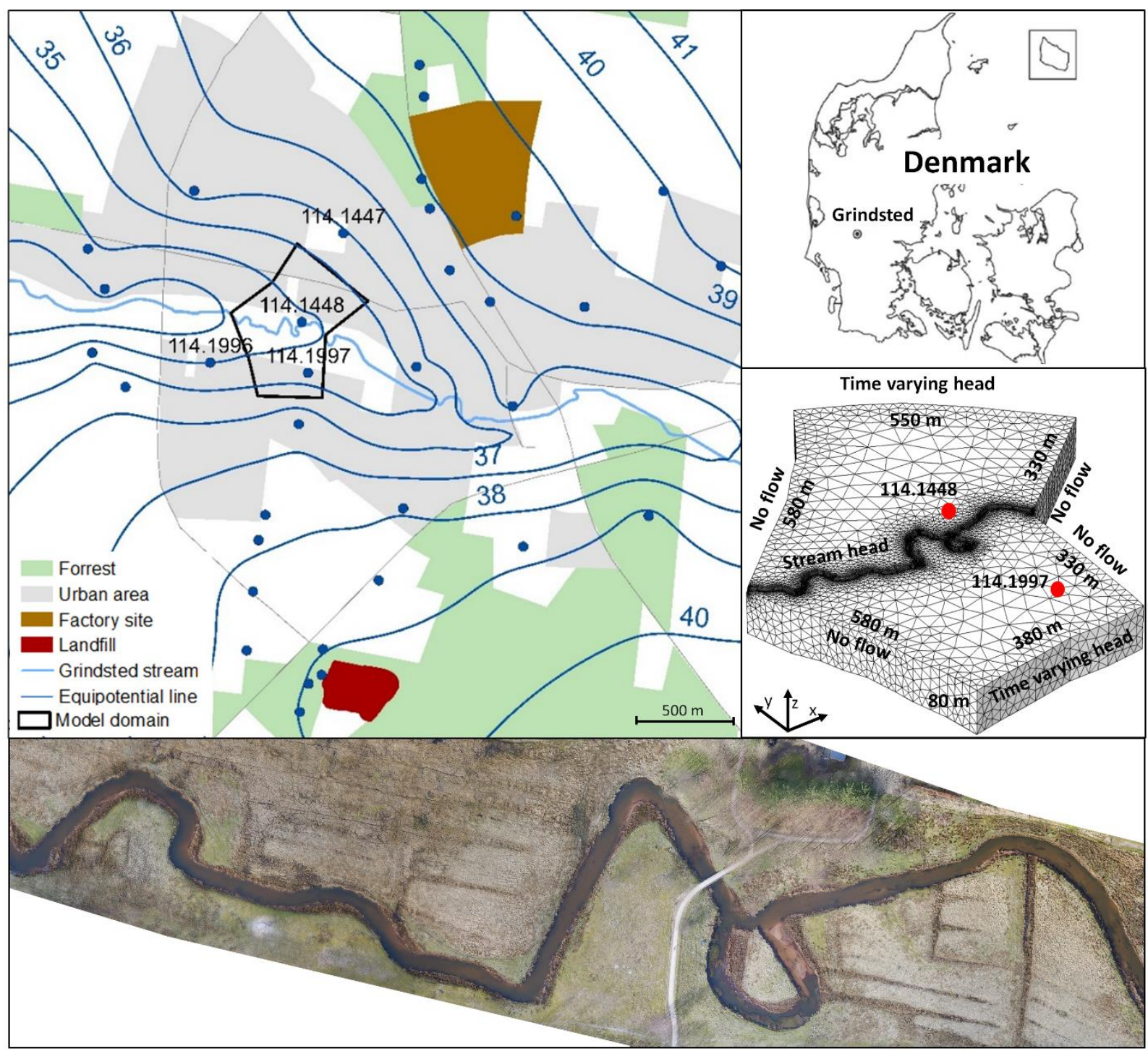

Figure 2: Overview of the Grindsted stream study site and model set up. The blue lines indicate the equipotential lines with an interval of $1 \mathrm{~m}$. The equipotential map is based on groundwater head measurements collected at the wells indicated by the blue dots. The name of the observation wells used to set up boundary conditions or for comparison with model results are shown on the map. The model domain area is defined by the black line. The bottom figure shows an orthophoto of the simulated stream reach. The middle right figure shows the model grid, the boundary conditions, the model size, and the location of boreholes in 


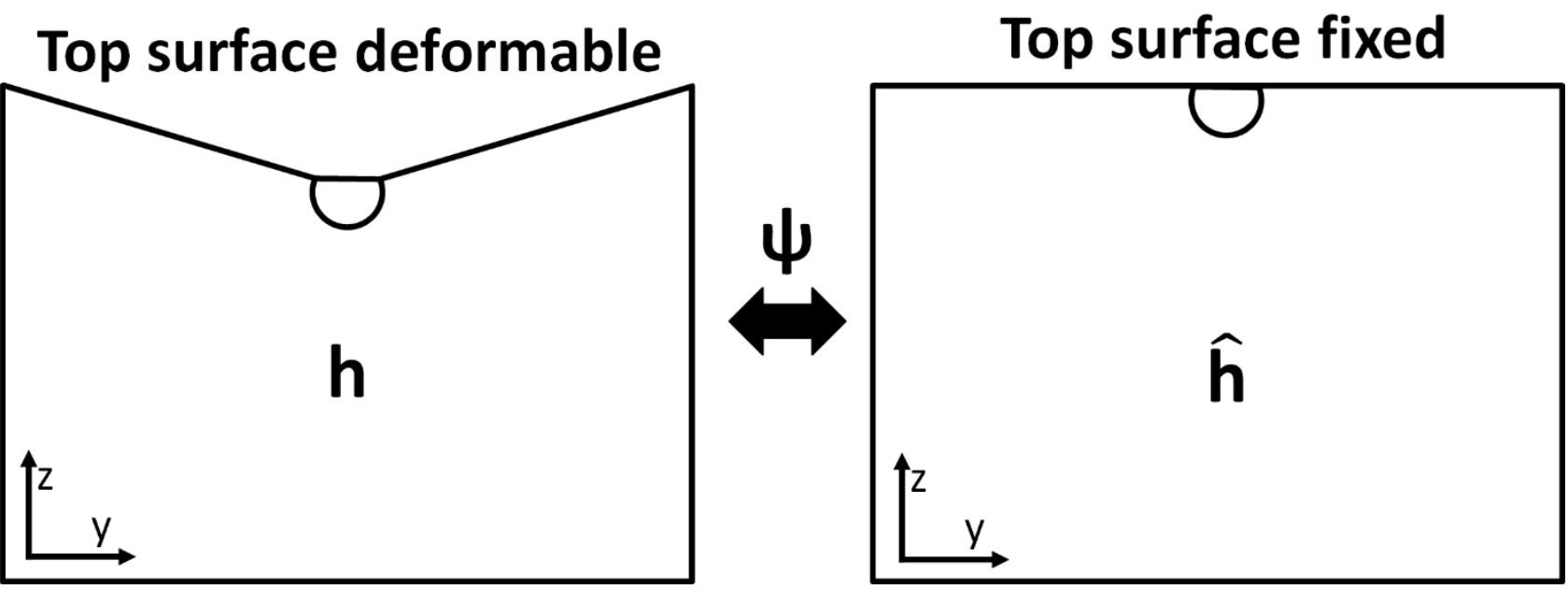

Figure 3: The coordinate transformation method for modeling unconditioned aquifers interacting with streams of Boon et al. (2016) employs a fixed domain (right) instead of the real deformable domain (left). A coordinate transformation $\Psi$ is used to map the governing equations between the two domains.

$\mathrm{J}_{\mathrm{yx}}=4$

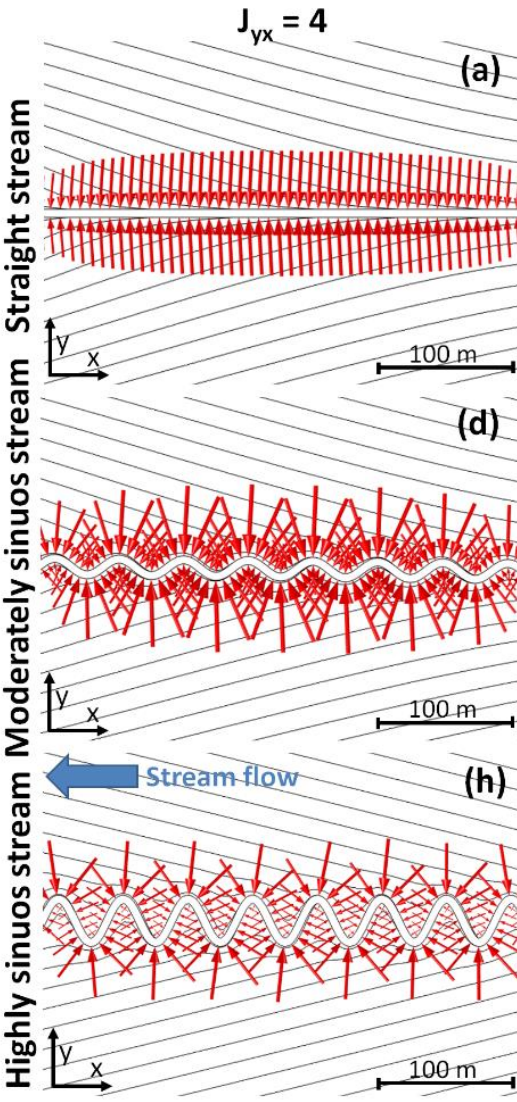

$\mathrm{J}_{\mathrm{yx}}=0.5$

要

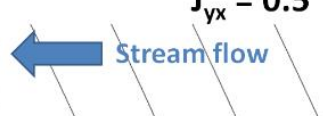

2015)

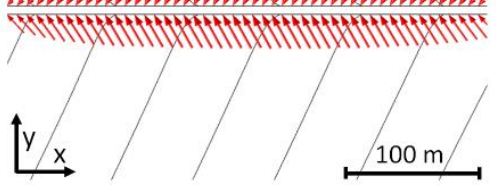

(e)

(b)

$\mathrm{J}_{\mathrm{yx}}{ }^{\text {north }}=0.5, \mathrm{~J}_{\mathrm{yx}}{ }^{\text {south }}=0.1$

stream flow

(c)

Figure 4: Groundwater discharge to the stream at the upper edge of the stream-aquifer interface shown by the red arrows, which are proportionate to the flow. The equipotential lines are indicated by the black lines and are separated by $0.05 \mathrm{~m}$ interval. Jyx represent the ratio between the hydraulic gradient in the $y$ and in $x$-direction. The moderately sinuous stream has

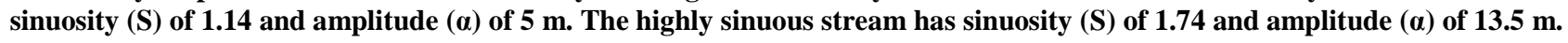



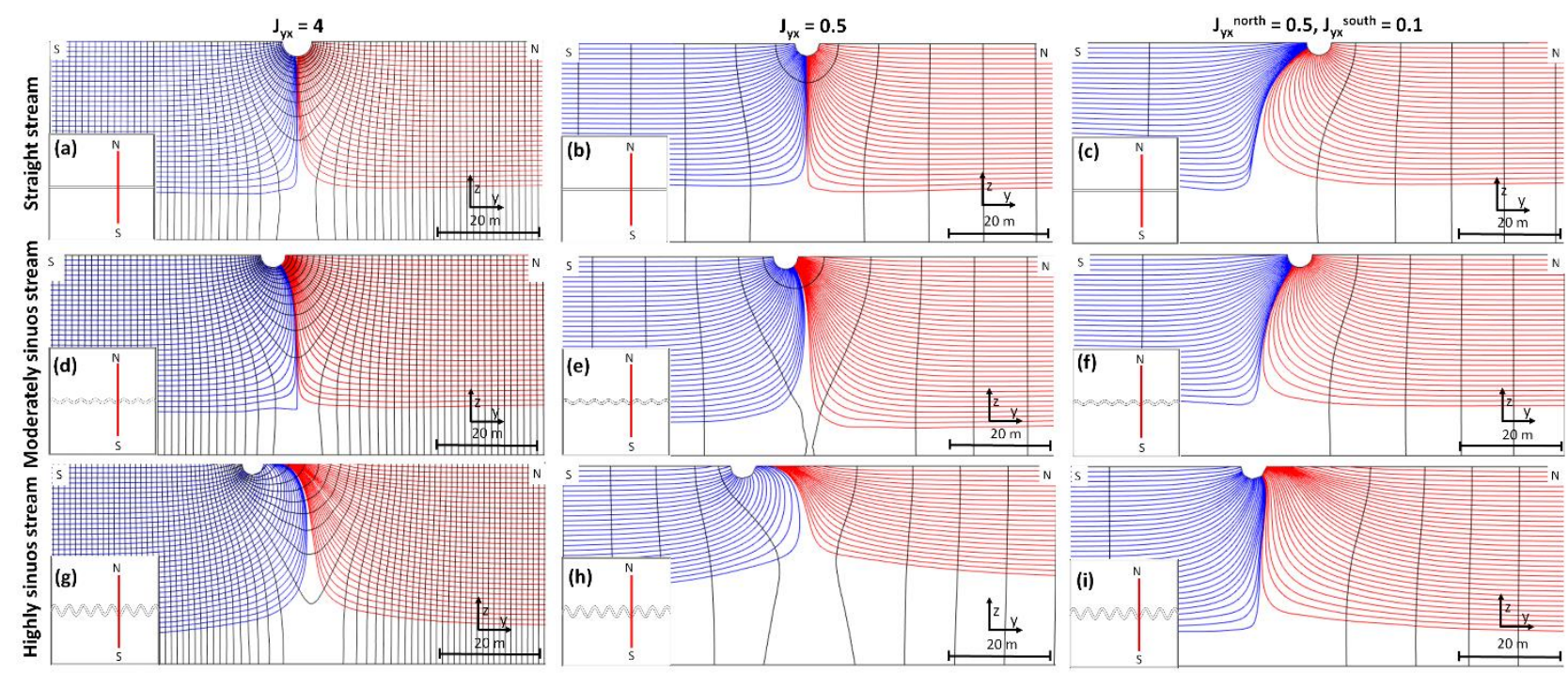

Figure 5: Groundwater paths from the northern (red lines) and southern (blue lines) sides of the stream at a vertical cross section perpendicular the stream located at the edge of a meander pointing south. The black lines show the equipotential lines separated by $0.005 \mathrm{~m}$. Jyx represent the ratio between the hydraulic gradient in the $y$ and in $x$-direction. The moderately sinuous stream has sinuosity (S) of 1.14 and amplitude $(\alpha)$ of 5 m. The highly sinuous stream has sinuosity (S) of 1.74 and

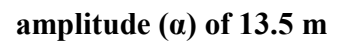

a) $5 \mathrm{~m}$ deep aquifer

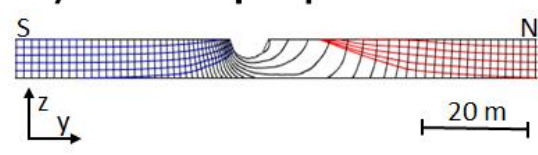

b) $40 \mathrm{~m}$ deep aquifer
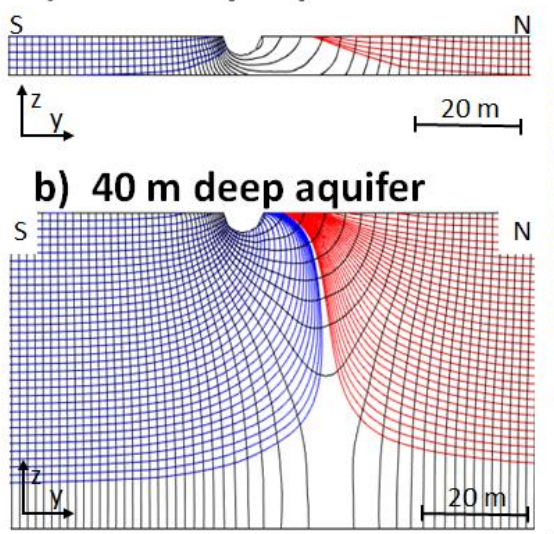

c) $80 \mathrm{~m}$ deep aquifer
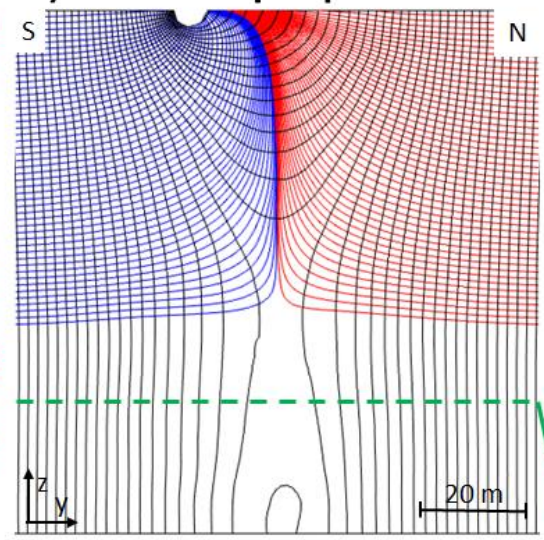

d) Horizontal groundwater flow at $\mathbf{6 0} \mathrm{mbgs}$

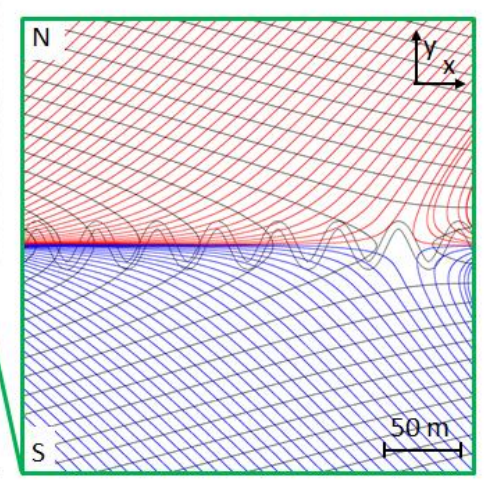

Figure 6: Effect of the aquifer thickness on the groundwater paths from the northern side of the stream (red lines) and from the southern side of the stream (blue lines) at three vertical cross sections perpendicular the stream and located at the edge of a meander bend pointing south $(a, b$, and $c)$. The black lines show the equipotential lines separated by $0.005 \mathrm{~m}$ interval. The green line in the $80 \mathrm{~m}$ deep aquifer (c) show the depth of the plan view section (d). The highly sinuous stream scenario with a Jyx 4 was employed. 


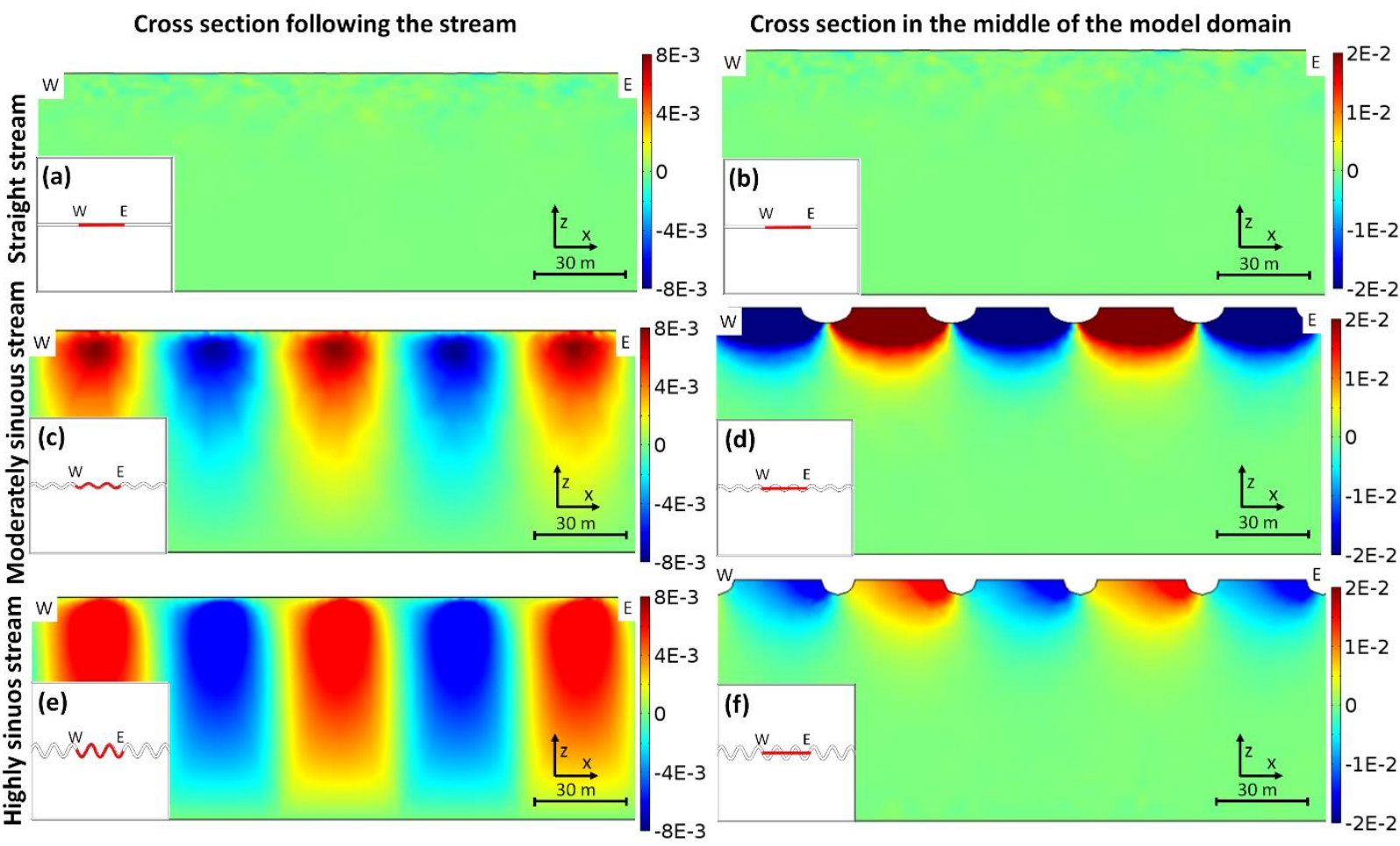

Figure 7: Groundwater flow in the $y$ direction $\left(q_{y}\right)$ in $\mathbf{m} / \mathbf{s}$ through vertical cross sections along the stream: the left panels show cross sections that follow the meandering stream path (a, $c$, and e), while the right hand panels show straight cross sections centered in the middle of the model domain (b, $d$, and f). Positive flow is directed to the north. The results are shown for the straight, the moderately sinuous and the highly sinuous stream with $J_{y x}=0.5$ and an aquifer thickness of $40 \mathrm{~m}$. The moderately sinuous stream has sinuosity $(S)$ of 1.14 and amplitude $(\alpha)$ of $5 \mathrm{~m}$ while the highly sinuous stream has a sinuosity $(\mathrm{S})$ of 1.74 and amplitude ( $\alpha$ ) of $13.5 \mathrm{~m}$. 


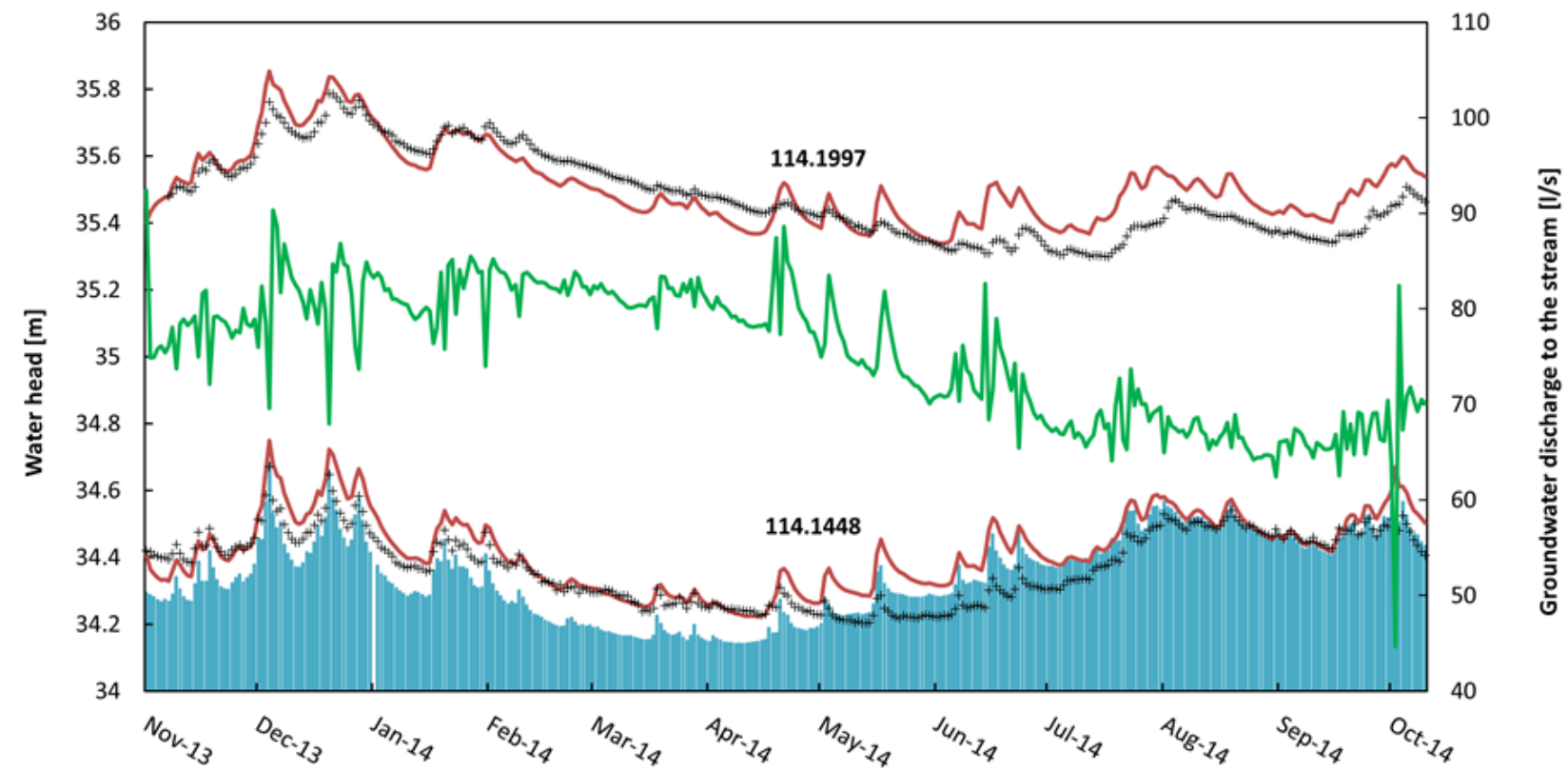

—observed stream water level + Observed groundwater head -Simulated groundwater head - Simulated groundwater discharge to stream

Figure 8: Model results from Grindsted stream compared to groundwater head data from well 114.1448 and 114.1997 (Figure 2). The stream water level at the closest location to well 114.1448 is indicated by the blue columns. The stream water level was calculated from the water level measurements at the Tingvejen station assuming a stream water slope, which was calculated at each day from the water level measurements at the Tingvejen and the Eg bro stations. The groundwater discharge to the stream (green line) is plotted to the secondary $\mathrm{y}$-axes, which starts at $40 \mathrm{l} / \mathrm{s}$, and is the integrated value of the discharges along the

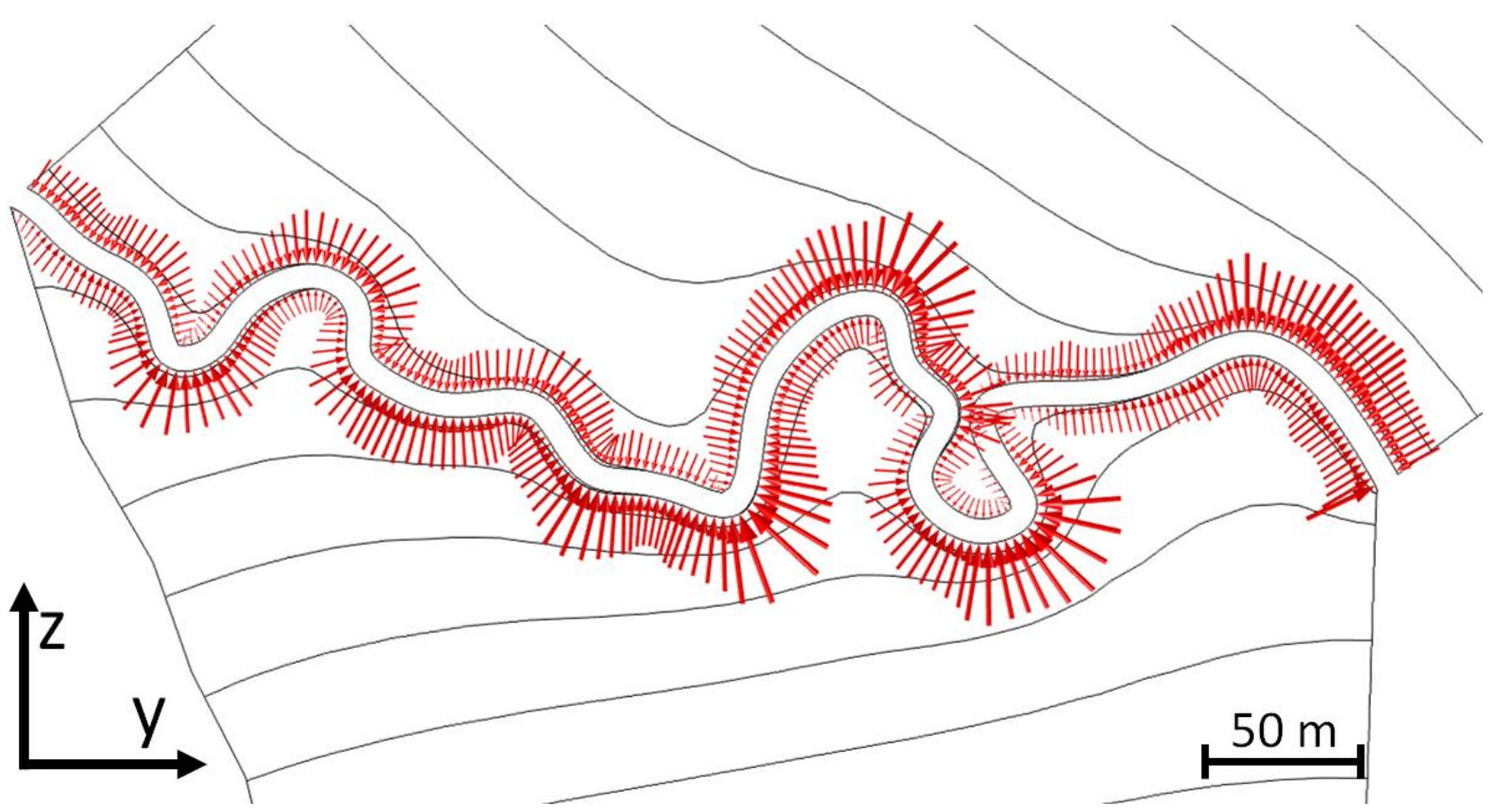

Figure 9: Horizontal groundwater flow at the upper edge of the stream-aquifer interface. The red arrows are proportional to the fluxes. The equipotential lines are separated by $0.2 \mathrm{~m}$. 


\section{Meander bend pointing north}

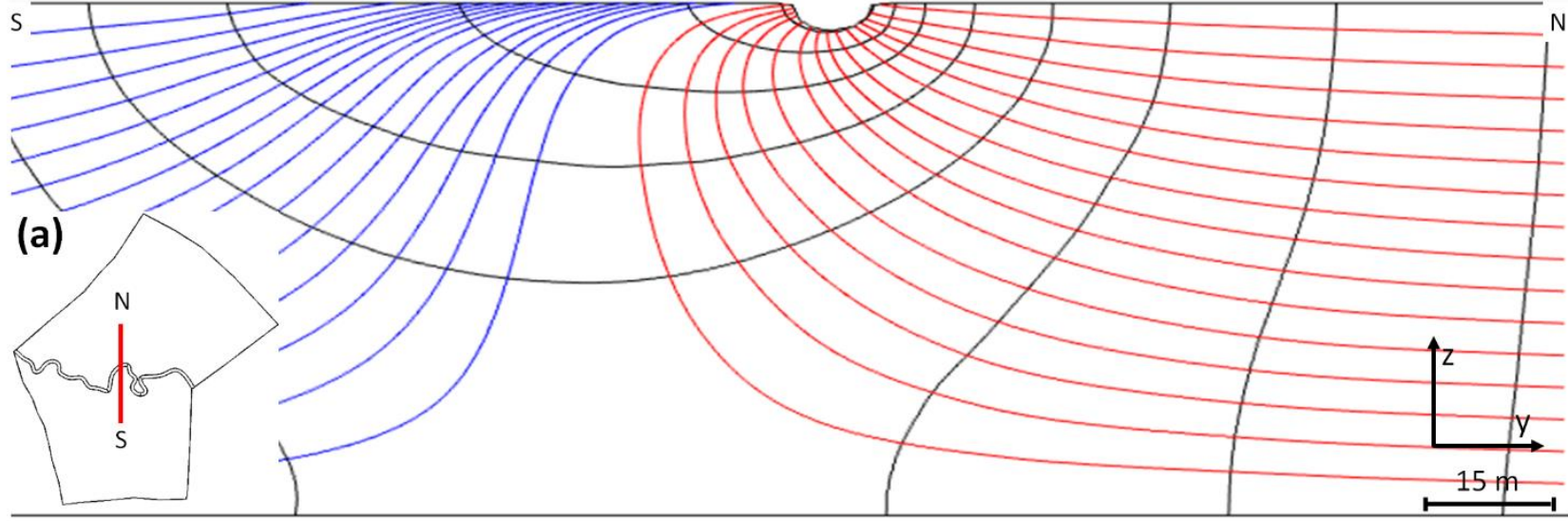

Meander bend pointing south

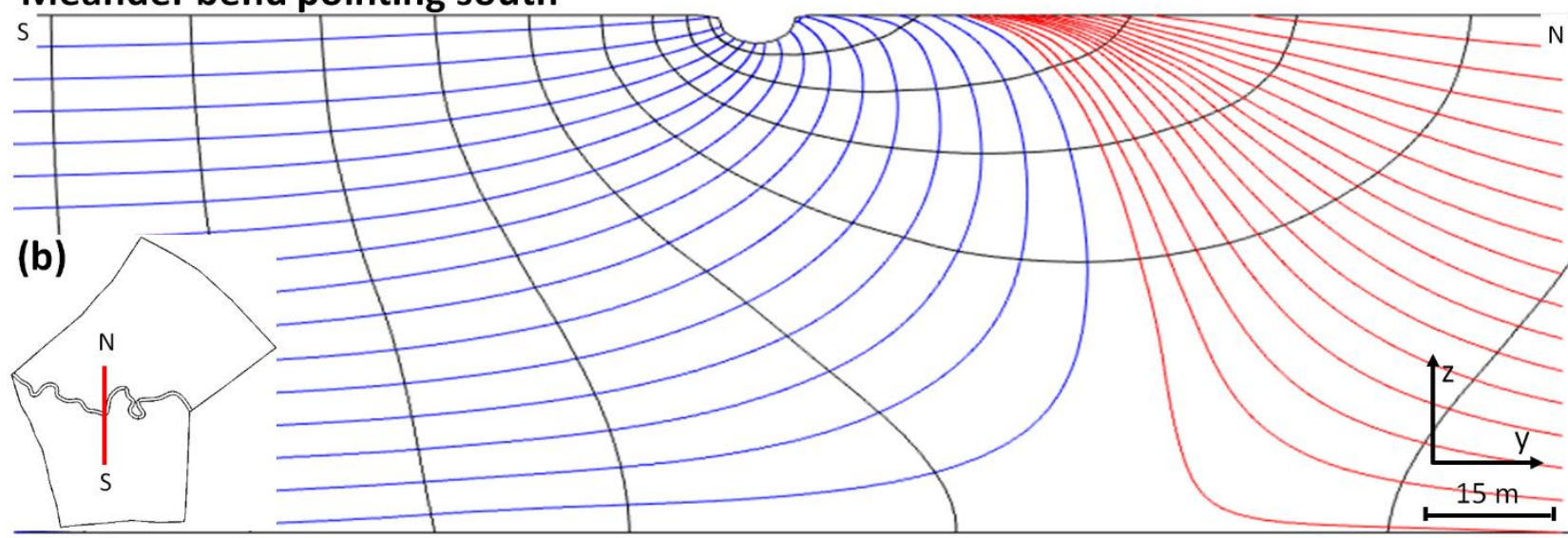

Figure 10: Groundwater paths from the northern side of the stream (red lines) and from the southern side of the stream (blue lines) at two vertical cross sections perpendicular the stream and located at the edge of a meander bend pointing north (a) and 